\title{
The Effect of Gender on the Bilingual and Bicultural Identity of the Iraqi EFL Learners' Recognition and Production of Request
}

\author{
Mohammed Jasim Betti ${ }^{1}$ \& Zainab Kadhim Hashim ${ }^{1}$ \\ ${ }^{1}$ Dept. of English, College of Education for Humanities, University of Thi-Qar, Nasiriya, Iraq \\ Correspondence: Mohammed Jasim Betti, University of Thi-Qar, Nasiriya, Iraq. Tel. 009647827505317. E-mail: \\ alseady2@gmail.com
}

Received: August 25, 2021; Accepted: September 2, 2021; Published: September 2, 2021

\begin{abstract}
This study examines the effect of gender on students' bilingual and bicultural identity in their recognition and production of request is studied. This means that it investigates to what extent the learners' mother tongue and culture influence their recognition and production of request in the EFL and the effect of gender on such an identity. The study aims at exploring and identifying the linguistic patterns of request in English used by Iraqi EFL learners, those patterns of request transferred from Iraqi EFL learners' mother tongue, and the Iraqi EFL learners' cultural patterns and cultural realization of request transferred from Arabic culture into the EFL. Some hypotheses of the study state that there is a bilingual and cultural identity in using request by Iraqi EFL learners, females are better than males in request perception and production and they are worse in Arabic monolingualism and monoculturalism, students are better in English monolingualism and monoculturalism than in the other request features, students' English monolingual and monocultural identity is more apparent in request perception than in production.
\end{abstract}

To validate or refute its hypotheses, a test comprising recognition and production has been constructed and applied to fifty Iraqi EFL learners at fourth year, Department of English, College of Education for Humanities, University of Thi-Qar at the academic year (2020-2021). After data analysis, some conclusions are arrived at.

The study concludes that Iraqi EFL learners are pragmatically incompetent and they have a bilingual and bicultural identity because of their mother tongue and culture interference.

Keywords: Gender, Bilingual and Bicultural Identity, Iraqi EFL Learners, Recognition, Production, Request

\section{Introduction}

\subsection{Introduce the Problem}

EFL learners have linguistic and cultural interference or negative transfer from their mother tongue into the FL. Linguistic transfer can be phonological, morphological, grammatical, lexical and pragmatic. Pragmatic interference is divided into pragmalinguistic and sociopragmatic or sociocultural interference (Eslami and Noora, 2008: 302).

Some studies reveal that Iraqi EFL learners do not have an adequate knowledge of pragmatic aspects in English especially if their interaction in a given situation is clearly manifested in the performance of the speech act of request when speaking in English which is an FL. They may seem less polite in the production of this face threatening act (henceforth FTA). However, different strategies of request are used by Iraqi EFL learner with regard to different situations. Likewise, the appropriateness of such strategies is affected by the learners' cultural backgrounds or mother culture (Abdul Sattar et al. 2009: 68).

\subsection{Research Questions}

The following questions are introduced in order to be investigated in this study:

1. What are the linguistic patterns of request in English?

2. To what extent are students better in English monolingualism and monoculturalism than in the other three types of request features?

3. What are the patterns of request realization used by Iraqi EFL learners? 
4. What are the linguistic and cultural patterns of request realization that are transferred from Iraqi EFL learners' mother tongue and culture into the EFL?

5. How are males and females different in request perception and production?

6. To what extent is the students' English monolingual and monocultural identity more apparent in request perception or in request production?

7. How are males and males different in Arabic monolingualism and monoculturalism use?

8. What is the effect of gender on the bilinguistic and bicultural Iraqi EFL Learners' recognition and production of request?

\subsection{Aims}

The study aims at the following:

1. Exploring the effect of gender on the bilinguistic and bicultural Iraqi EFL Learners' recognition and production of request.

2. Exploring the linguistic patterns of request in English.

3. Exploring the linguistic realization of request used by Iraqi EFL learners.

4. Identifying the linguistic patterns of request which are transferred from Iraqi EFL learners' mother tongue in the EFL.

5. Exploring the Iraqi EFL learners' cultural patterns of request.

6. Exploring the cultural realization of request transferred from Arabic culture into the EFL.

\subsection{Hypotheses}

In this study, the following hypotheses are given:

1. Students are better in English monolingualism and monoculturalism than in the other three types of request features.

2. Students' bilingualism and biculturalism are more than Arabic monolingualism and monoculturalism.

3. Females are better than males in request perception.

4. Students' responses fall in correct ones more incorrect ones in request production.

5. Females are better than males in request production

6. Students' positive request recognition is better than their production one.

7. Students are better in English monolingualism and monoculturalism than in the other three types of request features in both recognition and production.

8. There is bilingual and bicultural identity in using request by Iraqi EFL learners in both recognition and production.

9. Students' English monolingual and monocultural identity is more apparent in request perception than in production.

10. Females are better than males in Arabic monolingualism and monoculturalism.

\subsection{Significance}

The findings of this study might be used by teachers, EFL curriculum and textbook designers since the study highlights the importance of understanding linguistic and cultural differences between English and Arabic concerning the speech act of request.

\subsection{Limits}

The study is limited to examining the effect of gender on the bilinguistic and bicultural identity of the Iraqi EFL learners' mother tongue on the use of the speech act of request in the FL at the department of English, namely the fourth year students, College of Education for Humanities, University of Thi-Qar.

\subsection{Procedures}

The study is carried out through the following procedures:

1. Conducting a test to be applied to the Iraqi EFL undergraduate students of the fourth year at the department of English, College of Education for Humanities, University of Thi-Qar. 
2. Showing the test to the jury members in order to examine its validity and reliability.

3. Carrying out the test and analyzing its results.

\subsection{Definitions of Basic Terms}

\section{Bilingualism}

Bilingualism in this study refers to the learners' use of request strategies from both EFL and Arabic as the learners' mother tongue. It also refers to the effect of the learner's mother tongue in using the FL.

\section{Biculturalism}

In this study, biculturalism refers to the learners request strategy is being affected by the FL culture as well as the Arabic culture, which is the learner's mother culture.

\section{Iraqi EFL learners}

They represent the learners of English where this language has no internal or official function in their country. English is confined to classroom setting. It is taught for certain purposes such as communicating with "native speakers on inter-language users of the foreign language" (Betti and Al-Jubouri, 2015: 16).

\section{Literature Review}

\subsection{Requests}

\subsubsection{Definition of Request}

Requests are considered as speech acts which represent an intrusion on the hearer's territory. Therefore, they constrain his or her freedom from action (Reiter, 1997: 145). They can be seen within negative politeness if we are after Brown and Levinson (1987: 66) who see requests as FTAs because they are intended to threaten the addressee's negative face. Or, they can be seen within positive politeness if we follow Sifianian 1992 and Vazques Orta 1995 (cited in Reiter, 1997: 145). Searle (1976: 11) defines requests as one of the directive speech acts which represent the speaker's attempt to get the hearer to do something for him/her.

The illocutionary acts of requests enable the speaker to show the hearer that the speaker wants the hearer to perform the action using different linguistic forms. Those linguistic forms involve the head act of the request (request core) in addition to the peripheral elements that follow or precede the head act of the request in order to mitigate or aggravate the propositional content of this face threatening act (henceforth FTA). These peripheral elements represent modifications of requests which can be internal or external as it is in the following examples:

(1) May I ask you a favour? I need some money for my new computer. (external modification)

(2) Would you mind closing the window? (internal modification) (Koosh and Dastjerdi, 2012: 55)

\subsubsection{Speech Acts}

Birner (2013: 192) elaborates on this as "imperatives canonically have the illocutionary force of a command (or, relatedly a request, invitation, suggestion, etc.- essentially milder forms of a scale ranging from "suggestion" to a "command")". But, in the case of indirect speech act there is no correspondence between the linguistic form and the illocutionary force of the sentence; for example, to have a request in the form of interrogative or declarative. Searle (1979: 31-32) adds that linguistic forms, which are employed to encode a certain illocutionary act, are appropriate only if the felicity conditions are met or achieved. The request in understood depending on background information that is mutually shared by the speaker and the hearer in addition to the hearer's ability to make inference (ibid).

In sequential context of request, the speaker's utterance is context - shaped (it can be interpreted in terms of the context in which it is produced) and context-renewing (the speaker's utterance is seen as the immediate context for the next action performed by the participant) (Taleghani-Nikazm, 2006: 3). Thus, an appropriate context influences the right effect on the hearer. This is actually fulfilled through felicity conditions of request as follows:

1. There should be normal in- and out-put conditions which means both the speaker and the hearer speak the same language.

2. Propositional content conditions: the requested act is the future act of the hearer.

3. Preparatory condition: the speaker believes that the hearer is able to perform the request.

4. Sincerity condition: the speaker wants the hearer to perform the act. 
5. Essential condition: the utterance is considered as an attempt to get the hearer perform the requested act. Otherwise, the request is misunderstood (Fetzer, 2007: 9). These felicity conditions are seen as social and linguistic context categories (Fetzer, 2004: 5).

\subsubsection{Request Strategies}

When making a request, the speaker infringes on the hearer's need to be free from action and imposition. Hence, requests are performed directly and indirectly to minimize that imposition on the hearer. It is universally accepted that requests are realized by different linguistic forms such as imperatives, declaratives and interrogatives (BlumKulka and Olshtain, 1984: 201).

Requests consist of the head acts and the peripheral elements. The request head act is "the main utterance that functions as a request and can stand by itself without any supportive move, required to convey the request". The peripheral elements position is either before or after the request head act like hedges (e.g., adverbials such as 'kind of' and somewhat), address forms (e.g., names and titles), downgraders (e.g., downtoners and consultative devices) and upgraders (e.g., intensifiers such as adverbials which increase the force of the request like 'terribly'). The importance of the request and the peripheral elements lies in the idea that they can be used to compare the requestive behaviour of the participants in a particular study with the native speakers (Byon, 2004: 1675).

Blum-Kulka and Olshtain (1984: 202) present a taxonomy of nine request strategies which was then used by BlumKulka, House and Kasper (1989: 278-280) as the main classification scheme used in the Cross-Cultural Speech Act Realization Project (henceforth CCARP). These nine strategies are universally applicable for the categorization of request strategies. According to Blum-Kulka etal (1989:278-280), the following table shows the coding scheme of request strategies:

Table 1. Taxonomy of Request Strategies

\begin{tabular}{|l|l|l|l|}
\hline No. & $\begin{array}{l}\text { Request } \\
\text { Strategies }\end{array}$ & Definition & Examples \\
\hline 1 & $\begin{array}{l}\text { Mood } \\
\text { derivable }\end{array}$ & $\begin{array}{l}\text { "The grammatical mood of the locution } \\
\text { conventionally determines its illocutionary force of } \\
\text { the request." }\end{array}$ & $\begin{array}{l}\text { (18) Leave me alone. } \\
\text { (19) Clean up the Kitchen. }\end{array}$ \\
\hline 2 & $\begin{array}{l}\text { Explicit } \\
\text { performative }\end{array}$ & $\begin{array}{l}\text { What is intended is directly expressed by means of a } \\
\text { particular illocutionary verb. }\end{array}$ & $\begin{array}{l}\text { (20) I am asking you to move } \\
\text { your head. }\end{array}$ \\
\hline 3 & $\begin{array}{l}\text { Hedged } \\
\text { performative }\end{array}$ & $\begin{array}{l}\text { "The illocutionary verb denoting the requestive } \\
\text { intent, e.g., by modal verbs or verbs expressing } \\
\text { intention". }\end{array}$ & $\begin{array}{l}\text { (21) I'd like to/wanted to ask you } \\
\text { to present your paper a week } \\
\text { earlier. }\end{array}$ \\
\hline 4 & $\begin{array}{l}\text { Locution } \\
\text { derivable }\end{array}$ & $\begin{array}{l}\text { What is intended is immediately grasped from the } \\
\text { meaning of the locution. }\end{array}$ & $\begin{array}{l}\text { (22) Madam, you'll have } \\
\text { to/should/must/ ought to move } \\
\text { your car. }\end{array}$ \\
\hline 5 & $\begin{array}{l}\text { Want } \\
\text { statement }\end{array}$ & $\begin{array}{l}\text { "The utterance expresses the speaker's desire that the } \\
\text { event denoted in the proposition comes about." }\end{array}$ & $\begin{array}{l}\text { (23) I'd like to borrow your notes } \\
\text { for a little while. }\end{array}$ \\
\hline 6 & $\begin{array}{l}\text { Suggestory } \\
\text { formula }\end{array}$ & $\begin{array}{l}\text { What is intended is conveyed as a suggestion through } \\
\text { a specific linguistic formula. }\end{array}$ & $\begin{array}{l}\text { (24) How about cleaning up the } \\
\text { kitchen? }\end{array}$ \\
\hline 7 & $\begin{array}{l}\text { Query } \\
\text { preparatory }\end{array}$ & $\begin{array}{l}\text { "The utterance contains a reference to a preparatory } \\
\text { condition for the feasibility of the request, typically } \\
\text { one of ability, willingness, or possibility as } \\
\text { conventionalized in a given language. " }\end{array}$ & $\begin{array}{l}\text { (25) Can I borrow your notes? } \\
\text { (26) Could you possibly get your } \\
\text { assignment done this week? } \\
\text { (27) I was wondering if you } \\
\text { would give me a lift. }\end{array}$ \\
\hline 8 & $\begin{array}{l}\text { Strong hint } \\
\text { angat is intended is not directly relevant to the literal } \\
\text { anguistic form, but the linguistic form involves } \\
\text { request feasible. }\end{array}$ & $\begin{array}{l}\text { (28) Will you be going home } \\
\text { now? }\end{array}$ \\
\hline
\end{tabular}




\begin{tabular}{|l|l|l|l|}
\hline 9 & Mild hint & $\begin{array}{l}\text { What is intended is not conveyed literally. However, } \\
\text { it is inferred in terms of the context and the } \\
\text { knowledge activated in the hearer. }\end{array}$ & $\begin{array}{l}\text { (29) You've been busy, haven't } \\
\text { you? } \\
\text { In this example, the requester's } \\
\text { intent is to get the hearer to clean } \\
\text { the kitchen. }\end{array}$ \\
\hline
\end{tabular}

As for the levels of directness: from 1-5 are direct requests in which the illocutionary force is easily realized grammatically and semantically, from 6-7 are conventionally indirect requests in which the illocutionary force is understood through a specific linguistic convention in a particular speech community and they even depend on the context, and from 8-9 are non- conventionally indirect requests in which the illocutionary force of a request is carried out by communicating the locution act in a context either by indicating the object in order to achieve the request as in (3) or by depending on contextual cues as in (4):

(3) Why is the window open?

(4) It is cold in here (Daskalovska, et al., 2016, 56).

According to Trosborg $(1995,192-204)$, there are four main categories of request in addition to eight sub-strategies as follows:

\section{Indirect requests}

The action, which the speaker wants the hearer to do, is not mentioned directly, but it is inferred (Leech, 2014: 158). The desired action is left out in the case of mild hints:

(5) I am to be at the airport in half an hour (and my car has just broken down).

Or, the action is partially mentioned as in the case of strong hints:

(6) Shall you be using your car tonight ( Trosborg, 1995: 192).

Hints can either be statements or questions. Statement hints indicate the present situation "that call for the future action". They may seem impolite since they may show the hearers accusation of doing something:

(7) someone's taken my laptop.

(8) Oh dear, I can't find my laptop (Leech, 2014: 158).

2. Conventionally indirect requests (Hearer-oriented)

In this category, the hearer is the one to decide to comply with the request or not. Therefore, they are considered more polite than speaker-oriented requests. This category has two strategies which are hearer-oriented:

a. the first strategy can be either questioning the hearer's ability and willingness in addition to permission or statements of ability and willingness (Trosborg, 1995: 197-200):

(9) Can you reach this Jar for me, please? (Questioning ability)

(10) Will you do the shopping today? (Questioning willingness)

(11) May I interrupt for a moment? (permission)

Statements of ability and willingness indicate the speaker's anticipation of compliance with the request on the part of the hearer, for instance:

(12) Mary, you can clear the table now. (ability)

(13) you will proceed the headquarters immediately. (willingness)

b. The second strategy is the suggestory formula. Using this strategy, the speaker checks the hearer' cooperativeness and if there may be a condition that prevents him from doing the action:

(14) Why don't you come with me?

In (14), the requester checks the requestee's cooperativeness and if there might be a condition prevents him from coming with the requester.

For Leech (2014: 148-149), statements of indirect request strategies are as follows:

i. Prediction statement

(15) You will just fill out that work ticket. 
ii. Strong obligation statement

(16) You must record testing times for all three tests.

iii. iii. Weaker obligation statement

(17) You need to put the necklace on

iv. Volitional statement

(18) You've probably already skated but I want you to bend your knees.

v. Ability/possibility statements

(19) See, I want to become a very good cook. You can hang out with my mum for a while.

(20) You might wanna call ahead of time. Just make sure that the guys there (ibid).

3. Conventionally indirect requests (speaker-oriented conditions)

In this category, the speaker's interests or conditions are given priority and are placed over the hearer's conditions in the interaction. This category has two categories; they are statements of wishes/desires and statements of needs/demands. Requests in the form of statements of wishes/desires express the requester's intent more politely than requests in the form of statements of needs/demands which express the requester's intent more bluntly.

a- Statement of wishes and desires

(21) I would like to have some more coffee.

b- Statement of needs and demands

(22) I need a pen.

(23) I want you to sign this for me (Trosborg, 1995: 201-202)

\section{Direct requests}

In this category, the speaker expresses his request explicitly. This category involves three strategies:

a- The first strategy is the statements of obligation and necessity which exhibit the requester's authority through the use of 'should', ought to', 'have to' and 'must':

(24) You should / ought to / must leave now.

b- The second strategy is the performatives which include a performative verb conveying the illocutionary force. Performatives can either be hedged performatives (Al-Sheikh, 2006a: 71):

(25) I would like to ask you to leave?

Or, unhedged performatives:

(26) I ask / request / order / command you to leave (ibid: 202-203).

c- The third strategy includes imperatives and elliptical phrases.

To lessen the impositive force of imperatives, tags and the politeness marker 'please' could be added:

(27) Leave it to me, will you?

In elliptical phrases, the requester mentions the object he wants, for example:

(28) Two coffees, please (ibid: 204).

In order to mitigate the request, speakers use some modification that can be internal or external to the head act of request. Doing this, the face threating side of a request is softened and they, at the same time, enable the speaker to alter the force of the request in terms of their relation to a particular requestee (Woodfield, 2012: 11).

Internal Modification

Internal modification represents an internal means which the speakers have in addition to request strategies in order to mitigate the impact of the request on hearers. They involve the following:

A- Requestive perspective which can be as follows:

1. Hearer-oriented perspective in which the role of the hearer is emphasized:

(29) Could you tidy the kitchen soon?

2. Speaker-oriented perspective which emphasizes the role of the speaker: 
(30) Do you think I could borrow your notes from yesterday's class?

3. Speaker and hearer oriented perspective in which the request is realized from the two interlocutors' viewpoint:

(31) So, could we please clean up?

4. impersonal perspective in which the passivisation and people (e.g., they or one) are used as neutral agents:

(32) It might be not a bad idea to get it cleaned up (Daskalovska, et al. 2016: 57).

B- Syntactic and lexical internal modification which are included in the utterance or in the head act of the request to soften the bitter flavour of the request.

1. Syntactic downgraders involve the following:

a- Interrogative:

(33) Can I borrow your notes?

b- Negation:

(34) You couldn't give me a lift, could you?

This device may include interrogative

c- Subjunctive: the subjunctive mood of the verb is considered as a syntactic mitigation device:

(35) It might be better if you were to leave now (Blum-Kulka et al. 1989: 281-282).

d- Conditional clause which is used by the requester to make the request distant from reality:

(36) I'd like to borrow some of your records if you don't mind lending me them (Trosborg, 1995: 211; and AlSheikh, 2006b: 81).

e- Past tense that could be hypothetical and past time. Past tense hypothetical is expressed by the past tense auxiliaries (e.g., could, would, might) and the speaker believes the action may be performed:

(37) Would you help me if I were to ask you?

Past tense-past time: with the first person subject, the past time is a means of distancing in order to avoid the facing of the hearer's wishes:

(38) I wondered if you would mind if I recorded our conversation for the next few minutes ....

$\mathrm{f}$ - Aspect is a syntactic device which makes the request more tentative:

(39) "I was wanting to ask if you could mend this", she explained, and took the engine out of a box.

g- Tag questions reduce the impositive force of the bald-on- record command:

(40) Stop complaining, will you? (Leech, 2014: 169-170)

\section{Lexical/phrasal downgraders}

Lexical/phrasal downgraders are devices by which the impositive force of request is reduced on the lexical and phrasal levels. They involve the following:

a- The politeness maker 'please':

(41) Richard! Stop driving please!

b- Downtoners such as adverbs which express tentativeness (possibly, perhaps, maybe) diminshers (a bit, a little), adjectives (tiny, wee, teeny-weeny, ..., etc.) and nouns and verbs associated with smallness (amount, pop):

(42) Could you possibly give Ian, Zain and me the authority to work that one out (ibid: 160-161).

c- Consultative devices represent a ritualized formulae by which the requester tries to guarantee the requestee's cooperativeness. The ritualized formulae of this device like 'would you mind', 'do you think', and 'do you object':

(43) Do you think you could have the manuscript ready by tomorrow? (Trosborg, 1995: 212).

d- Understarters represent the devices by which the requester minimizes parts of the proposition with regard to either the action or the object:

(44) Could you tidy a bit before I start?

e- Hedges represent the devices that the requester uses in order not to impose the illocutionary force of the utterance on the hearer to do the required action: 
(45) It would really help if you did something about the kitchen.

f- Interpersonal markers which establish and maintain the interpersonal relation.

This involves phrases which are called cajolers like ('you know', 'I mean', 'you see') and appealers like 'right?' and 'okay?' (ibid: 214; Igaab, 2010b: 157):

(46) You wouldn't mind helping me, I mean, would you?

g- Subjectivizers refer to the elements that indicate the speaker's subjective opinion expressed in the request such as 'I am afraid', 'I wonder', 'I think', I believe' and 'I suppose' (Blum-Kulka, et al. 1989: 284 ):

(47) I'm afraid you are going to have to move your car.

h- Appreciative openings express the speaker's appreciation and positive attitude towards the hearer if the request is fulfilled, like 'I'd be so grateful if' and 'we'd really appreciate it if' (Leech, 2014: 163):

(48) I'd be very grateful if you would investigate this.

i- Hedged performative openings represent the opening main clause that reduces the impositive force of the performative. "The main clause "hedges" the performative, by introducing modality and sometimes interrogation" (ibid: 165):

(49) Could I ask Rotarian Jeff [ name] to propose a vote of thanks.

j- Negative Bias in which the verb 'mind' has a negative meaning by itself (ibid: 166):

(50) Do you mind if I use the ladder?

\section{External Modification}

External modifiers are considered as a piece of discourse which can stand by themselves doing the function of the request without the head act. They are added before or after the request that make it more polite. They are as follows (Betti, 1990: 47).:

a- Apologies which are added before the request:

(51) Excuse me, could you speak up just a little bit?

b- Thanks also indicate politeness:

(52) Can you do the next one James, thank you.

c- Vocatives (terms of address) have different functions such as getting attention of the hearer, signaling out the hearer and maintaining/establishing a social relationship with the hearer:

(53) Let's have a look mate (ibid: 171-172).

d- Supportive moves are statements supporting the request. These are as follows:

i. Grounder: it gives an explanation why the desired action should be fulfilled as in the given example:

(54) Judith, I missed the class yesterday, could I borrow your notes?

ii. Preparators which enable the hearer to notice the requester's intention:

(55) Arnold, would you do me a favour, please? Could you slip out [ pause] and retrieve our pianist? (ibid; 175).

iii. Disarmers represent the devices which are used to avoid the possible refusal of the request:

(56) I know you don't like lending out your notes, but could you make an exception this time?

iv- Expanders are the devices that exhibit tentative requests through the use of repetition:

(57) can you take him to the airport in the morning? ... Can you pick him up at 8:30? ( Uso-Juan and MartinesFlor, 2008: 351).

$\mathrm{v}$ - Promise of a reward is a device that guarantees the hearer's accomplishment of the request:

(58) Could you give me a lift home? I'll pitch in on some gas (Blum-Kulka, et al. 1989: 288).

vi- Getting a precommitment means that "the speaker precedes the act by an utterance that can count as an attempt to obtain a precommital":

(59) Will you do me a favour? Could you perhaps lend me your notes for a few days (Blum-Kulka and Olshtain, 1984: 205). 
vii- Sweetener refers to the requestee exaggeration when he appreciates the hearer's ability aiming at the hearer's compliance with the request:

(60) you have beautiful handwriting, would it be possible to borrow your notes for a few days? (ibid).

viii- Cost minimizers involve considering the cost on the hearer when complies with the request:

(61) Pardon me, but could you give me a lift, if you are going my way, as I just missed the bus and there isn't another one for an hour (ibid).

ix- Attention getters are items such as 'excuse me', 'hello' and 'Mr. Smith'. They represent items like apology, vocatives and greetings (Uso-Juan and Martinez-Flor, 2008: 315):

(62) Hey excuse me, listen (Blum-Kulka et al. 1989: 277).

\subsection{Bilingual Interference}

"Prior habits would either facilitate subsequent learning if the tasks were similar, or interfere with learning. There should be difference" (Miller, 1984: 97). This means that there are positive and negative transfer. Positive transfer promotes the learning process of the L2 because of the common features between L1 and L2 whereas the negative one hinders such a process (Chen, 2020: 307). Negative transfer or interference means that L1 patterns are different from L2 ones. This leads to a difficulty in acquiring the TL patterns (Carroll, 2008: 315). To locate where an interference or an error occurs, we have to specify where the error exists; that is, in which linguistic items and in which level in the TL overall system; for example, phonology, syntax, lexis, text or discourse (James, 1998: 105). Besides, there are interlingual errors which result from the difference between the L2 and the learner's mother tongue, and intralingual errors which result from insufficient learning of L2 rules or overgenarlizing them (SavilieTroike, 2012: 42).

\subsubsection{Phonological Interference}

Arabic and English phonemes are not identical, something which leads to interference (Rafik, 2012: 1). Moreover, knowledge of a particular sound system affects the listeners' perception of the language they are exposed to. This may entail difficulty in distinguishing phonetic contrasts that are not distinctive in their language (Carroll and Windsor, 2015: 54). Arabic speakers transfer their mother tongue features in pronunciation to the EFL (Swan and Smith, 2001: 196). Iraqi Arabic is one variety of Arabic that is used by the Iraqi people: educated and non-educated to communicate with each other. It is like other varieties which have their own phonetic and phonological systems with a number of consonants and vowels (Jasim \& Sharhan, 2013: 5; Betti and Igaab, 2019: 230).

In consonants, Arab learners may confuse the pronunciation of the following:

1. / f / and / $/$ / are pronounced / f / by Iraqi EFL learners of English.

2. / b / and / p / are also confused and / b / is used to represent both sounds in English. This is a case of phonological interference.

3. / $\mathrm{\eta} /$ is not found independently in Arabic and it is substituted by either / $\eta \mathrm{k} /$ or / ๆg / (Igaab, 2010a: 15).

4. / $\Theta$ / and / $\partial /$ are found independently in some Arabic dialects.

5. / 1 / is realized in both languages as dark and light, (Rafik, 2012: 14).

6. / $\mathrm{r} /$ in Arabic is flap where the tongue tip is in contact with the alveolar ridge. (Rafik, 2012: 17). Unlike English, Arabic learners pronounce / $\mathrm{r} / \mathrm{b}$ in the prevocalic position as in 'pretty' and 'sorry'.

7. Double consonants (Gemination) in Arabic interfere with their pronunciation in English; that is, Arabic learners put extra stress when pronouncing double consonants in English. This feature is transferred from the learner's mother tongue, e.g., 'allow' / al-law / (Alkhateeb, 2016; 99).

\section{ii- Consonant Clusters}

Arab learners of English transfer the patterns of their mother tongue when pronouncing English clusters. This is represented, for example, by the insertion of / I / to breakup the English consonant cluster in order to be easily pronounced, e.g., street / stri:t / becomes / sitri:t / (Betti and Al Jubouri, 2015; 154-155).

\section{iii- Suprasegmentals}

Suprasegmentals involve stress, rhythm, juncture (pause) and intention. Arabic learners of English find difficulty because word stress is not predictable in English, but it is fixed in Arabic. Additionally, the change of the stress position in a particular word will change the meaning in English, e.g., con'vict (verb) and 'convict (noun). This is 
the only case in which stress is significant in English. In Arabic, stress is used to differentiate between consonants and vowels whereas in English uses stress to differentiate between word class (Betti and Ulaiwi, 2018: 88).

As for rhythm, Arabic learners of English tend to have a heavy rhythm when speaking English, they do not use contracted forms and elision (Swan and Smith, 2001: 198-199).

\subsubsection{Lexical Interference}

Turaeva (2019 cited in Turaeva, 2020: 97) defines lexical interference as "all changes caused by interlanguage connection in the composition of the lexical inventory, as well as in the functions and use of lexical-semantic units, in their semantic structure". Lexical deviance, which may be the reason for lexical interference, means that the EFL learners' utterances do not match the FL lexical patterns:

$(63) * \ldots$ great black clouds gathered here and there in the pure sky.

In this sentence, the adjective does not collocate with the noun 'sky' in the FL and thus it should be substituted with 'clear' (Azzouz, 2013; 51). Here, the EFL learner uses 'great' because of lexical interference (Betti, 1993: $42)$.

\subsubsection{Grammatical Interference}

Grammatical interference is observed in the errors committed in the level of morphology and syntax (James, 1998: 154). Al-Badawi (2012: 537) finds that Arabic learners of English follow their L1 knowledge. Accordingly, they may fail to use the plural suffixes (-s/es) in particular noun phrases. Also, they fail to utilize the past tense suffix (-ed) in spite of the use of past tense indicators 'ago' and 'last' because the structure of verbs in the past is different in Arabic (Al-Seady, 1998a: 83).

Here are some studies that exhibit the grammatical interference on the part of Arabic learners of English who resort to their L1 knowledge:

i- Word order

The structure of Arabic and English sentences consists of a subject and a predicate. In English, the predicate may involve a verb only as in (63) or a verb in addition to some elements; such as the complement, the object and the adverbial as in (64):

(64) They are reading.

(65) She is clever.

In Arabic, the predicate may have a verb or not. Accordingly, we have verbal and nominal sentences. In verbal sentences, the position of the verb is either before or after the subject as in (65) and (66), but if "the subject is an indefinite noun it usually follows the predicate" as in (67):

(66) جاء المهندس (The engineer has come.)

(67) احمد وضع الكتاب على المنضدة (Ahmed put the book on the table.)

(68) في الحديقة رجل العندة) (there is a man in the garden.) (Aziz, 1989: 10-12).

Arab learners may transfer their L1 knowledge into English and thus they may not use the 'verb to do' in questions which also affect the sentence word order as in (69) while the proper English sentence is presented in (70):

(69) * Where Huda spend her summer vacation.

(70) Where does Huda spend her summer vacation? (Sabbah, 2015: 276).

Unlike English, Arabic adjectives follow the nouns. Thus, this rule may interfere with the English rule which is the adjective's preceding the noun. Hence, Arab students may follow their L1 rule as in (71) whereas the proper English word order is presented in (72):

(71) *Classroom large

(72) A large classroom (ibid).

ii- Coordination

iii- Tense

Ridha (2012: 33) reveals that most of simple present and past simple negative and interrogative sentences are incorrect because of $\mathrm{L} 1$ interference.

(73) *They was not speak frankly. 
(74) *Is she come early?

iv-Prepositions

Arabic learners of English tend to transfer their L1 equivalent prepositions to replace the appropriate English ones or to use prepositions in certain cases where no prepositions should be used in English:

$(75)^{*}$ In the fourth day

(76) * Think in him

(77) * Judge on thing

v- Articles

Arab learners use the definite article excessively because it is found in Arabic, but the indefinite articles are not:

(78) * The Saudi Arabia (Ali, 2007: 126).

vi- The copula

Arab learners tend to drop the copula and its related forms because it has no counterpart in Arabic as follows:

(79) The Bethlehem University like a small society (Khalil, 1985: 12).

\subsubsection{Pragmatic Interference}

Kasper (1992: 5) defines pragmatic transfer as "the influence exerted by learner's knowledge of languages and cultures other than L2 on their comprehension, production and learning of L2 pragmatic information". This means that the transfer of linguistic and nonlinguistic aspects of one's own language or what is called deficiency in pragmatic competence. He further divides pragmatic transfer into pragmalinguistic transfer which deals with linguistic forms that an individual uses to convey an illocutionary force and it is "language specific" and sociopragmatics which is the "sociological interface of pragmatics" and it is associated with sociology and it is "culture-specific" (ibid).

In Arabic, imperatives are used either for making polite requests or giving commands which is a thing reflected in Arabs' linguistic behaviour in English (Ghazzoul, 2019: 227):

(80) Eat or I will be angry (polite request).

(81) write your homework now (command)

On the other hand, imperatives are used for giving commands and directions in English. In Arabic, imperatives are usually softened lexically by certain devices (e.g. religious words) and certain mitigation devices which are adopted from literal translation of Arabic, e.g., 'itha mumkin' (if you can), 'mumkin' (can) and 'tigdar' (Are you able) (Al-Seady, 1998c: 73).

Influenced by their linguistic and cultural backgrounds, Arabic learners tend to use imperatives without any mitigation devices in the case of short distance relationships; such as, requesting friends or family members:

(82) Don’t go before me. (Ghazzoul, 2019: 227).

With or without mitigation, Iraqi EFL learners use imperatives in situations of asking a classmate for borrowing a notebook and the situation of asking their uncle to go on a vacation to the place where he lives and works as well (Al-Otaibi, 2015: 310):

(83) Take me with you.

The most prevalent syntactic mitigation device is the politeness marker 'please' in Saudi EFL learner's data (ibid). The same was observed by Hammadi (2019: 834) in Iraqi EFL learners' data:

(84) May I come with you?

Abdul Sattar and Farnia (2014: 47) reveal that grounders are the most external mitigation devices which are used by Iraqi learners of English. Grounders, which are performed by Iraqi learners, may be accompanied with address terms that define or specify the rank or the social status of the hearer as in the situation of asking a professor to delay the test for a student:

(85) Prof. I have something to do out of town. I want to postpone the test.

In this example, the speaker justifies or gives a reason for his/her desire to postpone the test.

Concerning sociopragmatic transfer, the use of bare imperatives demonstrates the imposition effect of this FTA on the hearer in Arabic. Doing this, learners assume "their L1 sensibilities that people are publically available to 
each other." Attention getters as mitigation devices are accompanied with L1 politeness to achieve a sort of intimacy with the hearer. The overuse of external modifiers, such as "imposition minimizers, apologies, grounders", is also transferred from L1 through which Arabs can even request social distant people because this is not disturbing in their L1 culture. However, the reverse is true for "independence politeness cultures" which employ the previous external modifiers other than grounders.

\subsection{Culture}

Culture is associated with people's understanding and interpreting of the world around them and there is not one specific definition to it since different fields investigate cultural areas. Consequently, definitions of culture are related to different fields like linguistics, anthropology, sociology and communication. For applied linguistics, understanding language, appropriateness of speech and rules of interaction are mainly realized through language users who use language in social context of culture (Decapua and Wintergerst, 2016: 12). There are certain elements that constitute culture such as "beliefs, values, norms, mores, taboos and attitudes."

1. Beliefs represent "an individual's convention about the world, conventions that are shaped by the culture of a person is raised in." People, in a particular culture, have nearly the same expectations of the way the world works and what reality is (DeCapua and Wintergerst, 2016: 20). In Arabic culture, Islamic religious beliefs are evidenced in performing requests by Arabs. Arabs believe that our life and the whole universe are controlled and protected by God. This construes the use of religious expressions in requests, e.g., (Alla j'afiiki, 'May Alla keep you healthy') (assalam 'alaikum, 'peace be upon you') and the formulaic expression (Mashaa Allah,'with God willing'). As for the last expression, Arabic people believe that mentioning such an expression makes people get rid of the harm caused by the evil eye as in the given example by a Saudi speaker:

(86) Mashaa Alla 'enti shatra bilhaasib, mumkin tshoofeen elli katabtuh .....?

"With God willing, you are skilled on the computer. Would you mind having a look at the report that I wrote ...? (Al-Ageel, 2016: 150-151; and Al-Seady, 2002: 15).

2. Values refer to what people assume or judge as good or bad, right or wrong and important or not. These judgments and assumptions affect the way people behave in their cultural setting. Furthermore, morals are closely associated with values. They refer to "religious guidelines that individuals try to follow in order to promote certain cultural values." Individuals' morals are determined by their values (DeCapua and Wintergerst, 2016: 22). For example, in Arabic culture, "men are the ones who are responsible to provide for their mothers with anything she might need and not the other way around."

Mothers in Arabic culture have a more special power than mothers in other cultures and men show all respect for them and try whatever to obey their mothers (ibid). Also, one of the Muslim's morals is to be cooperative and a life saver to other people even if they are not relatives. For instance, lending money is of more interest in English culture than in Arabic culture. In contrast, Arabs may postpone the money to be paid back and their interlocutors may refuse to take it back:

(87) I will return it tomorrow if God wills (Dendenne, 2016: 174)

3. Norms indicate "fixed behaviour patterns for members of a cultural group" which are shared among those members, such as the patterns of respect (DeCapua and Wintergerst, 2016: 23). In Arabic culture, the accepted norms of interaction are to show, for example, higher levels of respect and politeness towards the speakers' superiors. Showing politeness and respect, in Arabic culture, is closely associated with the risk of imposition, followed by the social power whereas the social distance is a less effective factor (Alzumor, 2012: $153)$.

4. Mores are formal norms or behaviours which are accepted by a cultural society and they are subject to social penalties.

5. Taboos are part of mores in that "they specify what is permissible or not" (DeCapua and Wintergerst, 2016: 24). In English culture, imperatives are considered as one of the linguistic taboos (Geis and Harlow, 1996: 145) because insulting people does not necessarily mean that you do something to them since insult can be verbally or non-verbally. Imperatives represent linguistic insult behaviour which is conveyed in the illocutionary force of the utterance since the speaker undermines the respect that the hearer expects on the part of the speaker (Anderson, 2019: 241). Swearing is not found in Arabic male and female participants' data (ibid).

6. Attitudes refer to people's opinions and reactions towards objects, ideas and other people. Attitudes are learnt through culture (DeCapua and Wintergerst, 2016: 25). 
Concerning politeness, Western cultures adopt negative politeness and use indirect linguistic strategies including more redressive actions than positive politeness. Positive politeness exists in cultures where politeness can be seen in terms of an individual's duty or commitment to his group (ibid: 13-14).

\subsection{Identity}

In SL context, Norton (2000 cited in Teng, 2019: 38) defines identity as how individual, his or her relationship to society, how that relationship can be constructed across time and space, and how he or she figures out the potential possibilities for future (ibid). Identity means "psychological process involved in the construction of the self with regard to group membership" (Hamers and Blanc, 2004: 200).

In the same way, Hamers and Blanc (2004: 202) distinguish social, cultural and ethnic types of identity. Social identity is to perceive who we are with regard to social group and the roles we have in society. Cultural identity is one side of our social identity which involves ancestry, territoriality, institutions, values, norms and language" which differentiate one cultural group from the other. ethnic identity is strongly associated with cultural identity.

\subsection{Cultural Interference}

An individual may judge a particular situation with his previous existing mental set which is culturally different from L2 native speaker's mental set. For example, offering coffee after a meal is a hint that a guest should leave soon which is expressed in polite way in some cultures. Cultural transfer is the result of cultural differences between learner's culture and the TL one. As a result, "people use their own culture rules and values to guide their words and deeds, even thoughts and they also use these as standards to judge the words and deeds of others" in other cultures (Zhu, 2008: 143). There are two kinds of cultural transfer:

i- Surface- cultural transfer deals with the linguistic forms in their cultural contexts and their use in communication which is subject to social and cultural context (ibid: 144). For example, Iraqi Arabic and Australian English have different conventional forms for the same mitigation devices such as verbal incentives (expressions of appreciation or supplication), closings (expressions of thanking and appreciation at the end of requests) and alerters (attention getters). Iraqi people have tendency to utilize expressions of supplication, like "Alla ye Khelic" (May God preserve you) in the case of verbal incentives and closings whereas Australian people tend to use expressions of appreciation and thanking for the same situation. As for alerters, it is observed that Iraqi people tend to use ficticious kinship terms, e.g., 'khewya' for (brother), titles, e.g., 'austath (sir) and first names in situations with different social factors (Al-Seady, 1998b: 62).

ii- Deep-structure transfer involves the influence of cultural values and thought patterns which operate on the psychological level. Such a transfer is not easy to cope with because it correlates with deeply rooted habits and thoughts (Zhu, 2008: 144).

L2 learners may be proficient in the TL and aware of the cultural values and traditions, but they still communicate inappropriately or unsuccessfully. This ineffective communication is condusive to deep structure or socio-cultural transfer (Liu, 1995: 256).

In intercultural communication, L1 negative transfer of linguistic rules and conventions leads to a difficulty in expressing and interpreting other parties' intended meaning (Song, 2012: 12). There might be similar linguistic strategies in L1 and L2, but the speaker should also judge the context in which these strategies are performed.

Besides, the choice of politeness strategies is determined by how different cultures assess the three social variables of social status, social distance and rank of imposition. For example, Iraqi EFL learners deviate in their assessment of the social variables from TL norms. They have no problems with the production of requests, but they exhibit a sociopragmatic failure because of $\mathrm{L} 1$ culture. They, for example, show direct requestive behaviour when asking another student in a nearby room to turn the music down:

(87) Please, turn the music down.

In this sentence imposition is highly perceived when the speaker gives priority to his own plans over the hearer's ones. Thus, students' requests are not appropriate if compared with native speakers' requests in terms of appropriateness of a particular situation of asking a mother's friend for more food at a friends' home is of a great imposition and impolite behaviour in Arabic culture (Abdul Sattar, et al. 2009: 68-69).

In Iraqi culture, people tend to use more mitigation devices when requesting someone with high social status (ibid: 43). This is evident in the Iraqi EFL learners' tendency to use more external modification devices when addressing their lecturers or professors like grounders, preparators and address terms which are often used with Islamic rituals, e.g., 'Alla-jkhalliik istath' (God may save you). Additionally, sweeteners are used with address terms like 'istathi al'azeez' (my dear teacher) and 'austathi alfathil' (my respectable professor) as in the given example: 
(88) My dear professor, I have a request? Is there any chance for postponing the test for any time you want? It was an emergent case and I couldn't study (Khattab, 2015: 695-696).

Iraqi people less use lexical/phrasal downgraders when they perform requests to their friends and family members because of the Islamic identity in their collectivist culture that fosters mutual obligation of Muslims towards each other. Therefore, Iraqi speakers expect their interlocutors cooperation and there is no need to make tentative requests (ibid: 44):

(89) Ureedu minke shaya. Hal bi-imkaniki an taqumi bil-tantheef.

[I] want to ask you for something. Are [you] able to do the cleaning.

(I want to ask you something. Can you do the cleaning).

Arabic speaker uses hearer-oriented requests when requesting a person who has equal or lower status and the degree of imposition not high:

(90) Could you lend me your notes (ibid: 101).

Grounder or the justification of request comes after the request in American English whereas it comes before the request in Jordanian Arabic. Jordanians' tendency to justify their request first is attributed to the idea that "requests are more face threatening than a grounder." Consequently, performing the request before the justification shows disrespect and bluntness in situations where the social factors of power and distance are considered (Al-Ali and Alalawneh, 2010: 328).

\section{Method}

This study aims to explore the linguistic patterns of request and its linguistic realization transferred from Arabic and investigate the cultural patterns of request and its cultural realization transferred from Arabic culture. In order to achieve this, the researcher conducts a test which contains forty items.

\subsection{Objectives of the Test}

The test aims are the same as the study ones. It aims to identify the linguistic and cultural patterns of request that are found in the performance of request by Iraqi EFL learners on the recognition and production levels.

\subsection{Test Construction, Description and Validity}

After constructing the test, it has been examined by the jury members (Note 1). Each member received a copy of the test in order to guarantee its validity. Since there must be an agreement of about (75\%) of the jury members with regard to test items validity, test items are approved of without being adjusted.

In order to evaluate all the informants' responses related to request, the test is constructed into two parts related to recognition and production levels. The recognition and production parts of the test include twenty items each. The forty items are selected from Quirk and Greenbaum (1973), Thomson and Martinet (1986), Leech and Svartvik (1994) and Leech (2014). The items cover the linguistic and cultural patterns that are used in the performance of request in Arabic and English.

In the recognition test, the informants are asked to choose one of the four options given. The options are characteristic of having the following four types of request features. Each option with a particular type of request features is in different position in each item:

1. English request strategies and English culture.

2. English request strategies and Arabic culture.

3. Arabic request strategies and English culture.

4. Arabic Request strategies and Arabic culture.

1- The use of English language and culture is characteristic of having strategies which have a sophisticated grammatical structure. Such as the use of speaker-oriented perspective and the progressive aspect as a mitigation device and the less use of hints strategies because they do not go in line with Gricean cooperative principle and the less use of grounders which often come after the request.

English culture is an individualistic one in which the individuals' rights and privacy are given priority. Thus, individuals are considered autonomous and independent. Consequently, a lot of mitigation devices especially syntactic ones are used to avoid one's negative face when requesting. All people have the same rights and duties in society. As a result, people's privacy should be taken into consideration when requesting people who might have an equal or lower social status than the speaker such as a family members or a taxi driver. 
Less mitigation devices are used when requesting people who might have a higher social status than the speaker. Besides, swearing is used in English culture, but it is forbidden in Arabic culture. These features are available in the following choices in each item: item No. 1 (a), No.2 (c) No. 3 (b), No. 4 (c), No. 5 (c), No. 6 (a), No. 7 (c), No. 8 (c), No. 9 (c), No. 10 (d), No. 11 (b), No. 12 (c), No. 13 (c), No. 14 (b), No. 15 (a), No. 16 (c), No. 17 (c), No. 18 (d), No. 19 (d), and No. 20 (b).

2- The English request strategies and Arabic culture is characteristic of using external mitigation devices which are transferred from Arabic culture and they reflect the Arabic identity such as kinship terms, Islamic formulas of appreciation and supplication. The excessive use of external mitigation devices is related to their excessive use in Arabic culture. These features are available in the following choices of each item: item No. 1 (d), No. 2 (d), No. 3 (c), No. 4 (a), No. 5 (b), No 6 (d), No. 7 (b), No.8 (b), No. 9 (b), No. 10 (b), No 11. (d), No.12 (d), No. 13 (b), No 14 (c), No. 15 (d), No. 16 (b), No. 17 (d), No. 18 (b), No. 19 (c), and No. 20 (d).

3- The Arabic request strategies and English culture are characteristic of using only the request strategies which re available in Arabic. Such as request is in the form of imperative and query preparatory indirect request strategy (Can you ...?) which is transferred from Arabic since the speaker, in Arabic, asks about the hearer's ability to do the required action.

Arabic speakers' less use of the past tense as a mitigation device because it is not used in Arabic. This construes the less use of past modals in request strategy such as 'Could you ....?' And 'Would you ...?' Additionally, the progressive aspect as a mitigation syntactic device is rarely used because it is not found in Arabic and the expression 'is it possible' (mumkin) is also used.

As for English culture, the speaker will resort to the less use of mitigation devices which is represented by 'please' which is also frequently used in Arabic. Moreover, the speaker resorts to the use of hints which are less used in English than in Arabic. He/she uses them in order to maintain his/her interlocutor's privacy. Doing this, the speaker's request will be indirect and the hearer will either comply with the request or deny it. These features are available in the following choices of each item: item No. 1 (b), No. 2 (a), No. 3 (d), No. 4 (b), No. 5 (d), No. 6 (b), No. 7 (d), No. 8 (d), No. 9 (d). No. 10 (a) No. 11 (c), No. 12 (b), No. 13 (d), No. 14 (d), No. 15 (b), No. 16 (d), No. 17 (b), No. 18 (a), No. 19 (b), and No. 20 (a).

4- The Arabic request strategies and Arabic culture is characteristic of using the same strategies which are previously mentioned concerning Arabic, but he/she resorts to the excessive use of mitigation devices especially external mitigation devices such as grounders, appreciation and supplication (sweeteners), greetings (aterters) and kinship terms (alerters).

As for Arabic culture, the speaker tends to employ direct request strategies with people who have equal or lower social status regardless of the degree of distance between them. However, the speaker tends to use indirect request strategies when requesting people who have a higher social status than the speaker. Thus, he/she uses the query preparatory indirect request strategy, e.g., 'Can you ...?' more than the request in the form of imperative with lots of mitigation devices.

These features are available in the following choices of each item: item No. 1 (c), No.2 (b), No. 3 (a), No. 4 (d), No. 5 (a), No. 6 (c), No. 7 (d), No. 8 (a), No. 9 (a), No. 10 (c), No. 11 (a), No. 12 (a), No. 13 (a), No. 14 (a), No. 15 (c), No. 16 (a), No. 17 (a), No. 18 (c), No. 19 (a), and No. 20 (c).

In the production test, the informants are asked to give a sentence about request concerning the situation given to them. The responses of the informants determine the type of data. They generally fall in one or more of the previously mentioned four types of request features.

\subsection{The Participants}

The number of informants participating in this study is (50) Iraqi EFL students divided equally to males and females at the fourth-year of the academic year (2020-2021) from department of English, College of Education for humanities, University of Thi-Qar, Nasiriya, Iraq. The participants are selected randomly. They have approximately the same linguistic expertise. The fourth-year students are chosen for the current study since they are regarded as more advanced than students in other stages.

Those students are accepted by the government in the College of Education. They are accepted in the department of English, often passing the ministerial exams with the average of 70-80 onward and their degrees in English starting from 70 onward. The traditional university lectures and their online teaching are in the morning. 


\subsection{Test Administration}

The test is not electronically administered. However, it is administered on the $26^{\text {th }}$ of May. The time allocated for responding to the test is two hours. The participants are asked to answer on the sheet of the test. Explanations are given to them in order to completely understand what they have to do.

\subsection{The Mathematical Means}

Simple calculations and percentages are used to show whether the differences are significant or not.

\section{Results}

This section involves the practical side of the study. It represents data analysis and discussion. It is divided into data analysis and discussion of the recognition and production parts of the test. The results of Iraqi EFL learners' recognition and production of request strategies are shown via tables and percentages because the current study is based on numerical data. The total number of responses in the recognition and production tests is 2000 :

1. English request strategies and English culture (English monolingualism and monoculturalism). This represents the correct responses.

2. English request strategies and Arabic culture (Biculturalism).

3. Arabic request strategies and English culture (bilingualism).

4. Arabic request strategies and Arabic culture (Arabic monolingualism and monoculturalism).

All the examples cited in the analysis are available ion Appendix 1.

\subsection{Data Analysis and Discussion of the Recognition Test}

This section involves data analysis and discussion of the recognition of the students' request.

\subsubsection{Recognition of the Students' Lingualism and Culturalism}

The percentage of correct responses as clear in Table (2) below represents only $13.75 \%$ which represents the number of students who have got adequate pragmatic competence compared to the incorrect ones which represents $36.25 \%$ :

Table 2. Occurrences and Percentages of the Students' Lingualism and Culturalism

\begin{tabular}{|c|c|c|c|c|c|c|c|c|}
\hline \multirow{3}{*}{$\begin{array}{l}\text { Item } \\
\text { No. }\end{array}$} & \multirow{2}{*}{\multicolumn{2}{|c|}{$\begin{array}{l}\text { Correct Responses } \\
\text { English } \\
\text { Monolingualism and } \\
\text { Monoculturalism }\end{array}$}} & \multicolumn{6}{|c|}{ Incorrect Responses } \\
\hline & & & \multicolumn{2}{|l|}{ Biculturalism } & \multicolumn{2}{|l|}{ Bilingualism } & \multicolumn{2}{|c|}{$\begin{array}{l}\text { Arabic Monolingualism } \\
\text { and Monculturalism }\end{array}$} \\
\hline & Occurrences & $\%$ & Occurrences & $\%$ & Occurrences & $\%$ & Occurrences & $\%$ \\
\hline 1 & 25 & 1.25 & 8 & 0.4 & 8 & 0.4 & 9 & 0.45 \\
\hline 2 & 7 & 0.35 & 10 & 0.5 & 6 & 0.3 & 27 & 1.35 \\
\hline 3 & 28 & 1.4 & 4 & 0.2 & 8 & 0.4 & 10 & 0.5 \\
\hline 4 & 6 & 0.3 & 27 & 1.35 & 7 & 0.35 & 10 & 0.5 \\
\hline 5 & 15 & 0.75 & 16 & 0.8 & 8 & 0.4 & 11 & 0.55 \\
\hline 6 & 12 & 0.6 & 15 & 0.75 & 10 & 0.5 & 13 & 0.65 \\
\hline 7 & 19 & 0.95 & 12 & 0.6 & 6 & 0.3 & 13 & 0.65 \\
\hline 8 & 16 & 0.8 & 13 & 0.65 & 5 & 0.25 & 16 & 0.8 \\
\hline 9 & 11 & 0.55 & 8 & 0.4 & 12 & 0.6 & 19 & 0.95 \\
\hline 10 & 9 & 0.45 & 16 & 0.8 & 7 & 0.35 & 18 & 0.9 \\
\hline 11 & 25 & 1.25 & 6 & 0.3 & 4 & 0.2 & 15 & 0.75 \\
\hline 12 & 9 & 0.45 & 7 & 0.35 & 23 & 1.15 & 11 & 0.55 \\
\hline 13 & 17 & 0.85 & 16 & 0.8 & 4 & 0.2 & 13 & 0.65 \\
\hline 14 & 14 & 0.7 & 9 & 0.45 & 10 & 0.5 & 17 & 0.85 \\
\hline 15 & 14 & 0.7 & 8 & 0.4 & 10 & 0.5 & 18 & 0.9 \\
\hline 16 & 16 & 0.8 & 13 & 0.65 & 2 & 0.1 & 19 & 0.95 \\
\hline 17 & 9 & 0.45 & 9 & 0.45 & 19 & 0.95 & 13 & 0.65 \\
\hline 18 & 7 & 0.35 & 12 & 0.6 & 18 & 0.9 & 13 & 0.65 \\
\hline
\end{tabular}




\begin{tabular}{|l|l|l|l|l|l|l|l|l|}
\hline 19 & 7 & 0.35 & 9 & 0.45 & 17 & 0.85 & 17 & 0.85 \\
\hline 20 & 9 & 0.45 & 8 & 0.4 & 16 & 0.8 & 17 & 0.85 \\
\hline Total & 275 & 13.75 & 226 & 11.3 & 200 & 10 & 299 & 14.95 \\
\hline
\end{tabular}

The above table refutes hypothesis (1) since English monolingualism is the lowest compared to the three incorrect types of request features. It is the worst of all the types of features. This small number of students use the English monolingualism and monoculturalism. This means that they use English linguistic and cultural strategies. Thus, they realize the sophisticated structure of English request strategies and how they are used in relation to a particular situation with a good assessment of the sociological factors, namely thee social power, the social distance and the rank of imposition. Likewise, they assess such variables in terms of the English culture rather than the Arabic one.

The highest frequency alternative, of the correct responses which shows the study informants' English monolingual and monocultural identity, exists in item (3.b) and it reflects the highest positive use of this type of request features. The number of occurrences for Item (3) is (28) which makes $(1.4 \%)$ out of $(13.75 \%)$ of the students' correct responses.

Alternative (3.b) represents the use of English request strategy which is the conventional indirect strategy (query preparatory) following speaker-oriented perspective as a mitigation device which does not refer explicitly or bluntly that the hearer will do the required request (Leech, 2014: 141). The politeness marker 'please' is also used as a lexical downgrader. As for external mitigation, the sentence (I need to prepare for the next lecture) is a grounder that gives you a justification for the request and it usually comes after the request. In this situation, the interlocutors have an equal power and they are familiar but not intimates. Besides, the rank of imposition is high. That is why, higher levels of indirectness are employed. The degree of politeness increases when requesting those who are familiars but not intimates (see Kasper, 1992: 166). Hence, the students realize that native speakers of English employ higher levels of indirectness and a lot of supportive moves which is a characteristic of their horizontal or individualistic culture. Such a culture is affected by the social distance more than the social power.

As clear in Table (2), the percentage (14.95\%), which represents the students' Arabic monolingual and monocultural identity, is higher than that of the English monolingual and monocultural identity $(13.75 \%)$ which represents the correct responses. This refutes hypothesis (2). Moreover, the same percentage $(14.95 \%)$ is also much greater than those percentages which indicate the incorrect responses in the other two types of request features; such as, biculturalism with a percentage of $(11.3 \%)$ and bilingualism with a percentage of $(10 \%)$. Thus, the students who suffer from their mother and culture interference is much greater than the number of those who have an adequate pragmatic and even those who have a sort of deficiency in their pragmatic competence whether on the pragmalinguistic level or on the sociopragmatic level in the recognition of request.

Additionally, if the percentages of incorrect responses in three types of request features are added to each other, the result will be $(36.25 \%)$. This percentage of the incorrect responses altogether is so greater than that of the correct responses as (13.75\%). Consequently, negative achievement of the students is higher than their positive achievement. One main reason for this result is that English is taught as an FL. Definitely, the students have limited opportunities to practise requesting in real life situations. Thus, it is normal that they subject to their mother tongue and culture interference. Even if internet access is available, most students find it difficult to communicate with natives because the poor level they have got in English. This poor level in English is due to the idea that teaching English focuses on grammatical rules more than pragmatic ones starting from the early years of education up to the university level.

Arabic monolingualism and monoculturalism which represents the highest of all the four groups reaching (299), $(14.45 \%)$. This number of students have a deficiency in their pragmatic competence due to their mother tongue and mother culture inferences.

Item (2.b) receives the highest positive occurrence of this type of request features. The responses reflecting the positive employment of this type are found in item (1.c). The number of occurrences of alternative (2.b) is (27) with the percentage $(1.35 \%)$. In $2 \mathrm{~b}$, the alternative (b) represents the students' perception of the request in terms of their mother tongue and culture. In this alternative, the speaker makes a long winded request, a thing which is related to a high context culture in which speakers' intents are not directly stated. Also, doing this, the speaker prepares the hearer to agree with his request. At the same time, the speaker uses an Arabic direct request strategy (You lend me your car) which is transferred from Arabic. Using direct strategies means that Arabic people expect other people's help because people are available to each other in their collectivist culture. Also, a lot of mitigation is used like apology 'sorry', kinship terms 'brother' and grounders. Moreover, swearing are reflected in making requests whereas they are not used in the English culture. 
As for biculturalism, the total number of study informants' incorrect responses is (226) making (11.3\%). These students have a good knowledge of the request strategies which are employed in English but they transfer their cultural traits in the perception of requests and they perceive the English request strategies in the light of their assessment of the sociological variables in terms of their hierarchical and collectivist culture in every situation they may encounter.

The highest occurrence in the students' incorrect responses reflecting their negative employment of this type of request features, is found in item (4.a) (27) representing (1.35\%). In the situation of Item (4a), the speaker imposes his her request to use the direct request strategies (the bare imperative) whatever the language is. In (4.a), the speaker reduces the impositive force of the imperative syntactically by adding a tag question (will you?) which is an English strategy (Leech, 2014:170). However, the speaker transfers an Arabic cultural trait which is the speaker's excessive use of kinship terms (e.g., sister) with familiars and unfamiliars, a thing which is related to their Islamic identity. Hence, the students succeed in realizing the English syntactic mitigation device. However, they go back to their mother culture as for the lexical mitigation device (kinship term).

On the other hand, the number of occurrences of alternative (3.c) is (4)

representing (o.2\%). In item (3.c), the interlocutors have equal social powers and they are familiars but not intimates and the imposition is high and the speaker may infringe on the hearers' privacy. Thus, the speaker uses an English indirect request strategy that is syntactically mitigated (e.g., the interrogative and the past modal 'would'). With regard to the Arabic culture, the speaker uses some external mitigation devices that are transferred from Arabic; like, the vocative 'kinship term/brother' and the expression of supplication 'If God wills, you got in time'. This expression shows one of the Arabic cultural beliefs in the bad effect of the evil eye and once the name of God is mentioned, this effect will remove. Also, the speaker employs an imposition minimizer 'if this doesn't cause you any trouble' which can be used in English and Arabic as a mitigation device.

Bilingualism in students' incorrect responses represents (200) making (10\%) and this indicates the students' bilingual identity of request perception. This means that the students have a sort of deficiency in their pragmatic competence which is on the pragmalinguistic level rather than on the sociopragmatic one. They resort to transfer their Arabic request strategies, mainly the imperative and the query preparatory ( can you) to ask about the hearer's ability to do the future act of request. On the other hand, they may stick to the English culture concerning the assessment of the sociological variables in the perception of request. Thus, requests are mitigated to maintain the interlocutors' negative face even if they are inferiors.

The highest negative occurrence for bilingualism, is found in item (12.b) in the students' data. In contrast, the lowest positive occurrence is in item (16.d) where only two occurrences reveal the negative use of bilingualism, the number of occurrences of alternative (12.b) is (23) making (1.15\%). In Item (12.b), the choice of alternative (b) represents the use of an Arabic request strategy which is often used when ordering something in public places where most people use elliptical requests or even imperatives. The aforementioned strategies may be, sometimes, without any mitigation because of the hierarchical structure of the Arabic society. Besides, it is a normal behaviour in such a situation and it does not cause any imposition for a waiter in a restaurant as it is his duty to serve people what they order. However, the speaker resorts to an English cultural conduct which is the use of extra mitigation with such an elliptical request represented by an apology (Excuse me) and the politeness marker 'please' maintains the interlocutors' negative face even if bringing coffee is a waiter's duty and it is a feature of the negative politeness culture where people have the same rights and obligations.

\subsubsection{The Male-Female Recognition of Request}

The total number of the correct responses, which determine the study informants' English monolingual and monocultural identity of request on the recognition level, exhibit a difference between the two sexes as illustrated in Table (3) below:

Table 3. Male-Female Occurrences and percentages of English Monolingualism and Monoculturalism in Request Recognition

\begin{tabular}{|c|c|c|c|c|}
\hline \multicolumn{5}{|c|}{ Correct Responses } \\
\hline \multirow[b]{2}{*}{ Item No. } & \multicolumn{2}{|l|}{ Males } & \multicolumn{2}{|l|}{ Females } \\
\hline & Occurrences & $\%$ & Occurrences & $\%$ \\
\hline 1 & 13 & 0.65 & 12 & 0.6 \\
\hline 2 & 3 & 0.15 & 4 & 0.2 \\
\hline 3 & 15 & 0.75 & 13 & 0.65 \\
\hline
\end{tabular}




\begin{tabular}{|l|l|l|l|l|}
\hline 4 & 2 & 0.1 & 4 & 0.2 \\
\hline 5 & 7 & 0.35 & 8 & 0.4 \\
\hline 6 & 2 & 0.1 & 10 & 0.5 \\
\hline 7 & 7 & 0.35 & 12 & 0.6 \\
\hline 8 & 8 & 0.4 & 8 & 0.4 \\
\hline 9 & 6 & 0.3 & 5 & 0.25 \\
\hline 10 & 4 & 0.2 & 5 & 0.25 \\
\hline 11 & 11 & 0.55 & 14 & 0.7 \\
\hline 12 & 4 & 0.2 & 5 & 0.25 \\
\hline 13 & 9 & 0.45 & $\mathbf{8}$ & $\mathbf{0 . 4}$ \\
\hline 14 & 7 & 0.35 & 7 & 0.35 \\
\hline 15 & 5 & 0.25 & 9 & 0.45 \\
\hline 16 & 7 & 0.35 & 9 & 0.45 \\
\hline 17 & 4 & 0.2 & 5 & 0.25 \\
\hline 18 & 3 & 0.15 & 4 & 0.2 \\
\hline 19 & 5 & 0.25 & 2 & 0.1 \\
\hline 20 & 5 & 0.25 & 4 & 0.2 \\
\hline Total & 127 & 6.35 & 148 & 7.4 \\
\hline
\end{tabular}

The number of male vs female informants' correct responses is (127) representing (6.35\%) and (148) representing $(7.4 \%)$ respectively. This means that females are better than males in request perception. Thus, hypothesis (3) is accepted. Females outperform males concerning positive achievement in request perception within the same group.

The highest positive occurrence, which proves the females' English monolingual and monocultural identity, exists in item (11.b) $(0.7 \%)$., and the lowest frequency in females showing the lowest positive use of this type of request features is in item (19.d).

In item (11), alternative (b) represents the use of an English request strategy (query preparatory) with the past tense of 'can' (could) as a syntactic mitigation device in addition to lexical mitigation devices like the politeness marker 'please' and an apology 'excuse me'. The use of extra mitigation devices is to make the request as tentative as possible when requesting people (e.g., a taxi driver) whose social power is lower than the speaker's. This is adopted by the individualistic culture where egalitarianism is a feature which guarantees equal rights for every citizen.

Concerning Arabic monolingualism and monoculturalism, the total number of male and female informants' incorrect responses indicate a slight difference between the two sexes as illustrated in Table (4) below:

Table 4. Male-Female Occurrences and percentages of Arabic Monolingualism and Monoculturalism in Request Recognition

\begin{tabular}{|c|c|c|c|c|}
\hline \multirow[b]{2}{*}{ Item No. } & \multicolumn{2}{|l|}{ Males } & \multicolumn{2}{|l|}{ Females } \\
\hline & Occurrences & $\%$ & Occurrences & $\%$ \\
\hline 1 & 5 & 0.25 & 4 & 0.2 \\
\hline 2 & 14 & 0.7 & 13 & 0.65 \\
\hline 3 & 3 & 0.15 & 7 & 0.35 \\
\hline 4 & 5 & 0.25 & 5 & 0.25 \\
\hline 5 & 8 & 0.4 & 3 & 0.15 \\
\hline 6 & 7 & 0.35 & 6 & 0.3 \\
\hline 7 & 7 & 0.35 & 6 & 0.3 \\
\hline 8 & 9 & 0.45 & 7 & 0.35 \\
\hline 9 & 11 & 0.55 & 8 & 0.4 \\
\hline 10 & 9 & 0.45 & 9 & 0.45 \\
\hline 11 & 8 & 0.4 & 7 & 0.35 \\
\hline 12 & 5 & 0.25 & 6 & 0.3 \\
\hline 13 & 6 & 0.3 & 7 & 0.35 \\
\hline 14 & 8 & 0.4 & 9 & 0.45 \\
\hline 15 & 12 & 0.6 & 6 & 0.3 \\
\hline
\end{tabular}




\begin{tabular}{|l|l|l|l|l|}
\hline 16 & 10 & 0.5 & 9 & 0.45 \\
\hline 17 & $\mathbf{8}$ & 0.4 & 5 & 0.25 \\
\hline 18 & 6 & 0.3 & 7 & 0.35 \\
\hline 19 & 10 & 0.5 & 7 & 0.35 \\
\hline 20 & 7 & 0.35 & 10 & 0.05 \\
\hline Total & 158 & 7.9 & 141 & 7.05 \\
\hline
\end{tabular}

The male informants' responses which are (158) representing (7.9\%) are higher than that of the female ones, (141) representing $(7.05 \%)$. This means that the negative achievement in this type of request features is higher in males' incorrect responses than in females' ones. Consequently, male informants have much tendency to transfer their L1 request strategies and their cultural traits in the recognition of requests. They have an inadequate pragmatic competence on the pragmalinguistic and sociopragmatic levels.

The highest and lowest in males' incorrect responses are in items (2.b) and (3.a). Item (2.b) was previously explained. Item (3.a), the speaker uses an Arabic request strategy 'can you' which is literally translated 'Tiqdar' and transferred into English. Also, the imposition is high and the speaker may infringe on the hearers' privacy. With regard to Arabic culture interference, the speaker makes a long winded request to prepare the hearer to comply with his request and to maintain a common ground between them.

Regarding biculturalism, the number of responses, which specify the study informants' bicultural identity, indicate a difference between males and females in the same type of study (see Table 5 below)

Table 5. Male-Female Occurrences and percentages of Biculturalism in Request Recognition

\begin{tabular}{|c|c|c|c|c|}
\hline \multicolumn{5}{|c|}{ Incorrect Responses } \\
\hline \multirow[b]{2}{*}{ Item No. } & \multicolumn{2}{|l|}{ Males } & \multicolumn{2}{|l|}{ Females } \\
\hline & Occurrences & $\%$ & Occurrences & $\%$ \\
\hline 1 & 3 & 0.15 & 5 & 0.25 \\
\hline 2 & 6 & 0.3 & 4 & 0.2 \\
\hline 3 & 1 & 0.05 & 3 & 0.15 \\
\hline 4 & 17 & 0.85 & 10 & 0.5 \\
\hline 5 & 7 & 0.35 & 9 & 0.45 \\
\hline 6 & 10 & 0.5 & 5 & 0.25 \\
\hline 7 & 8 & 0.4 & 4 & 0.2 \\
\hline 8 & 6 & 0.3 & 7 & 0.35 \\
\hline 9 & 2 & 0.1 & 6 & 0.3 \\
\hline 10 & 8 & 0.4 & 8 & $\begin{array}{l}0.4 \\
\end{array}$ \\
\hline 11 & 4 & 0.2 & 2 & 0.1 \\
\hline 12 & 3 & 0.15 & 4 & 0.2 \\
\hline 13 & 9 & 0.45 & 7 & 0.35 \\
\hline 14 & 7 & 0.35 & 2 & 0.1 \\
\hline 15 & 5 & 0.25 & 3 & 0.15 \\
\hline 16 & 7 & 0.35 & 6 & 0.3 \\
\hline 17 & 5 & 0.25 & 4 & 0.2 \\
\hline 18 & 6 & 0.3 & 6 & 0.3 \\
\hline 19 & 3 & 0.15 & 6 & 0.3 \\
\hline 20 & 7 & 0.35 & 1 & 0.05 \\
\hline Total & 124 & 6.2 & 102 & 5.1 \\
\hline
\end{tabular}

The total number of the males' incorrect responses in biculturalism is (124) making (6.2\%) whereas that of females is (102) making (5.1\%). This indicates that the difference between males and females, who have negative achievement represented by their incorrect choices, is significant. As such, it is higher than that of females. Consequently, the study males can realize the English request strategies in so far as culture is concerned when requesting. However they have much tendency to perceive such strategies in terms of their cultural assessment of the sociological variables of social power, social distance and rank of imposition. 
The highest and lowest occurrences of male's incorrect responses of the use of biculturalism are in item (4.a) (17) and item (9.b) (2) making (0.1\%) respectively. In Item (9.b), the speaker uses an English request strategy which is a mitigated imperative with a tag question 'will you'. Yet, the English speaker may not use this strategy in this situation as it may refer to priority of one's needs on those of others. Following Arabic culture, the effect of this strategy on the hearer is normal because of the collectivist nature of their society.

With reference to bilingualism, the total number of male informants' incorrect responses is less than that of female informants as illustrated in Table (6):

Table 6. Male-Female Occurrences and percentages of Bilingualism in Request Recognition

\begin{tabular}{|c|c|c|c|c|}
\hline \multicolumn{5}{|c|}{ Incorrect Responses } \\
\hline \multirow[b]{2}{*}{ Item No. } & \multicolumn{2}{|l|}{ Males } & \multicolumn{2}{|l|}{ Females } \\
\hline & Occurrences & $\%$ & Occurrences & $\%$ \\
\hline 1 & 4 & 0.2 & 4 & 0.2 \\
\hline 2 & 2 & 0.1 & 4 & 0.2 \\
\hline 3 & 6 & 0.3 & 2 & 0.1 \\
\hline 4 & 1 & 0.05 & 6 & 0.3 \\
\hline 5 & 3 & 0.15 & 5 & 0.25 \\
\hline 6 & 6 & 0.3 & 4 & 0.2 \\
\hline 7 & 3 & 0.15 & 3 & 0.15 \\
\hline 8 & 2 & 0.1 & 3 & 0.15 \\
\hline 9 & 6 & 0.3 & 6 & 0.3 \\
\hline 10 & 4 & 0.2 & 3 & 0.15 \\
\hline 11 & 2 & 0.1 & 2 & 0.1 \\
\hline 12 & 13 & 0.65 & 10 & 0.5 \\
\hline 13 & 1 & 0.05 & 3 & 0.15 \\
\hline 14 & 3 & 0.15 & 7 & 0.35 \\
\hline 15 & 3 & 0.15 & 7 & 0.35 \\
\hline 16 & 1 & 0.05 & 1 & 0.05 \\
\hline 17 & 8 & 0.4 & 11 & 0.55 \\
\hline 18 & 10 & 0.5 & 8 & 0.4 \\
\hline 19 & 7 & 0.35 & 10 & 0.5 \\
\hline 20 & 6 & 0.3 & 10 & 0.5 \\
\hline Total & 91 & 4.55 & 109 & 5.45 \\
\hline
\end{tabular}

The total number of the males' responses is (91), (4.55\%) while females' responses are (109), (5.45\%). This means that the negative achievement in this type of request features is higher in female's incorrect responses than in male's incorrect ones. As a result, female informants have much tendency to use their L1 request strategies which is an indicator of the deficiency in the pragmalinguistic level of the pragmatic competence in the recognition of request. The item (17.b) receives the highest negative frequency for bilingualism in the evening females' data. The number of occurrences of alternative (b) is (11) representing $(0.55 \%)$ of females responses in this type of request features:

In item (17.b), the speaker uses a request strategy that expresses his desire and it represents a literal translation of his request in Arabic. Following the English culture, this request is less mitigated if compared with those in alternatives (a) and (d) where the speaker tends to exhibit exaggeration in the mitigation of request when requesting a university doctor who has got high academic and social statues. However, excessive use of mitigation devices is regarded as a sort of subservience in English culture. On the other hand, the number of occurrences for item (16.d) is (1), (0.05) and it has already been referred to.

\subsection{Data Analysis and discussion of the Production Test}

\subsubsection{Students' Production of Request Lingualism and Culturalism}

The categorization of the informants' responses into the four types of features in request production is judged by the same linguistic features characteristic of each type of features. The number of correct responses is 295 
representing 14.75 while the incorrect ones is 705 representing 35.25. This refutes hypothesis 4 since students responses fall in incorrect responses more than those in correct ones in request production (Table 7):

Table 7. Occurrences and Percentages of Students' Production of the Types of Request Features

\begin{tabular}{|c|c|c|c|c|c|c|c|c|}
\hline \multirow{3}{*}{$\begin{array}{l}\text { Item } \\
\text { No. }\end{array}$} & \multirow{2}{*}{\multicolumn{2}{|c|}{$\begin{array}{l}\text { Correct Responses } \\
\text { English } \\
\text { Monolingualism and } \\
\text { Monoculturalism }\end{array}$}} & \multicolumn{6}{|c|}{ Incorrect Responses } \\
\hline & & & \multicolumn{2}{|l|}{ Biculturalism } & \multicolumn{2}{|l|}{ Bilingualism } & \multicolumn{2}{|c|}{$\begin{array}{l}\text { Arabic Monolingualism } \\
\text { and Monoculturalism }\end{array}$} \\
\hline & Occurrences & $\%$ & Occurrences & $\%$ & Occurrences & $\%$ & Occurrences & $\%$ \\
\hline 1 & 10 & 0.5 & 3 & 0.15 & 0 & 0 & 37 & 1.85 \\
\hline 2 & 15 & 0.75 & 2 & 0.1 & 1 & 0.05 & 32 & 1.6 \\
\hline 3 & 18 & 1.9 & 0 & 0 & 0 & 0 & 32 & 1.6 \\
\hline 4 & 27 & 1.35 & 3 & 0.15 & 5 & 0.25 & 15 & 0.75 \\
\hline 5 & 11 & 0.55 & 0 & 0 & 0 & 0 & 39 & 1.95 \\
\hline 6 & 11 & 0.55 & 0 & 0 & 0 & 0 & 39 & 1.95 \\
\hline 7 & 15 & 0.75 & 0 & 0 & 0 & 0 & 35 & 1.75 \\
\hline 8 & 19 & 0.95 & 5 & 0.25 & 11 & 0.55 & 15 & 0.75 \\
\hline 9 & 7 & 0.35 & 2 & 0.1 & 0 & 0 & 41 & 2.05 \\
\hline 10 & 11 & 0.55 & 2 & 0.1 & 0 & 0 & 37 & 1.85 \\
\hline 11 & 9 & 1.45 & 1 & 0.05 & 1 & 0.05 & 39 & 1.95 \\
\hline 12 & 43 & 2.15 & 3 & 0.15 & 0 & 0 & 4 & 0.2 \\
\hline 13 & 22 & 1.1 & 0 & 0 & 1 & 0.05 & 27 & 1.35 \\
\hline 14 & 10 & 0.5 & 0 & 0 & 1 & 0.05 & 39 & 1.95 \\
\hline 15 & 2 & 0.1 & 3 & 0.15 & 0 & 0 & 45 & 2.25 \\
\hline 16 & 12 & 0.6 & 0 & 0 & 0 & 0 & 38 & 1.9 \\
\hline 17 & 21 & 1.05 & 1 & 0.05 & 1 & 0.05 & 27 & 1.35 \\
\hline 18 & 12 & 0.6 & 0 & 0 & 0 & 0 & 38 & 1.9 \\
\hline 19 & 8 & 0.4 & 1 & 0.05 & 0 & 0 & 41 & 2.05 \\
\hline 20 & 12 & 0.6 & 0 & 0 & 0 & 0 & 38 & 1.9 \\
\hline Total & 295 & 14.75 & 26 & 1.3 & 21 & 1.05 & 658 & 32.9 \\
\hline
\end{tabular}

The occurrences of English monolingualism and monoculturalism cited above indicate that they can produce appropriate requests which are characterized by English grammatical structures and request strategies in relation to the right situation including the sociological variables of social power and distance, rank of imposition, and their judgment of these variables is in terms of the English culture rather than the Arabic one.

The situations, which have the highest and lowest frequencies of the correct responses and exhibit the study informants' English monolingual and monocultural identity in request production are situations (12) and (15) which represent the most negative and positive employments of the English request strategies and English culture traits respectively. The number of occurrences for situation (12) is (43) making (2.15\%) of the students' correct responses. Some examples of the students' correct responses for item (12) of production are below:

(1) Could I leave early tomorrow. I have got some work outside the town?

(2) Excuse me, sir. Can I leave early tomorrow? It is an emergency.

In (1), the study informant uses an English request strategy (query preparatory) which involves syntactic mitigation or downgraders like the interrogative, the past model 'could' and the speaker - oriented request. Doing this, the speaker intensifies the distance between the two interactants. S/he also uses a grounder which often comes after the request to justify her/his request to downgrade its impositive force.

In (2), the informant employs the same type of English request strategies (query preparatory) following the speaker-oriented perspective as an indirect request. Other mitigation devices are apology 'excuse me', terms of address 'Sir' and a grounder 'it is an emergency'. Following the English culture, the participants are direct in stating their intended requests because of the English context culture and that they do not use excessive mitigation because of the English individualistic culture which guarantees equal right and duties for each citizen. This is in 
contrast with the hierarchical Arabic culture where the requesters tend to employ higher levels of indirectness and mitigation represented by long winded requests when addressing their employers, bosses at work, etc.

As for item (15) of the production test representing the lowest occurrence, the number of the occurrences for this item is (2) making $(0.1 \%)$. An example of the students' correct responses for item (15):

(3) Could you explain your subject, please?

In this situation, the speaker's social power is high and there is social distance between the interactants. The respondent uses an English indirect request strategy 'could you' which is syntactically mitigated using an interrogative and the past of the modal 'could' in addition to the internal lexical mitigating device 'please'. The respondent follows the English cultural features; that is, his request should be mitigated even when talking to inferiors because of the English individualistic and horizontal culture that employs higher levels of indirectness regarding the social distance more than the social power.

The highest responses of the incorrect request production are in Arabic monolingualism and monoculturalism 658 occurrences compared to 26 and 21 ones for biculturalism and bilingualism respectively. In Arabic monolingualism and monoculturalism, the of informants' incorrect responses is (658) representing (32.9\%), referring to the students' negative achievement in the fourth type of request features. Such students are subject to their mother tongue and mother culture negative transfer in request production which is the worst case among other types of request like bilingualism and biculturalism.

The highest occurrence of the students' Arabic monolingual and monocultural identity in request production exists in situation (15). Such a highest occurrence exhibits the negative use of this type of request features. However, the lowest occurrence is found in situation (12) reflecting the positive use of Arabic monolingualism and monoculturalism. Some examples of situation (15) of the production test are the following:

(4) Explain what subject you have chosen for your research.

(5) Can you explain the subject that you have chosen for your research?

In this situation, the hearer has higher social power than the speaker and there is a social distance between the two. In the above sentences, the speaker uses Arabic request strategies, namely the imperative without any mitigation and the query preparatory which is literally translated. Following his hierarchical culture, the student does not use any mitigation to mitigate the rank of imposition since higher levels of directness are used when requesting inferiors.

An example of the students' incorrect responses for item (12) is the following:

(6) I apologize, Sir. I got across. I want to go home early tomorrow.

In this situation, the speaker's social power is less than that of the speaker and there is a social distance between the two. Besides, the imposition is high on the hearer. The students' request refers to a literal translation of Arabic using want statement and other mitigation devices; like, apology 'I apologize', a vocative 'address term/Sir' and a sentence to minimize the imposition on the hearer. Doing this, the student considers the hierarchy of the social relationships in Arabic culture.

With regard to biculturalism, the total number of the informants' responses is (26) making (1.3\%) representing the students' incorrect responses whose students have a bicultural identity and negative achievement in request production. In other words, these students can produce the English request strategies. Nevertheless, they transfer their Arabic cultural traits when making requests in English. They, therefore, make a link between these strategies and their Arabic cultural assessment of the sociological variables in every situation they may encounter.

The highest frequency situation having bicultural identity is situation (8) $(5 ; 0.25 \%)$ which is an evidence of the negative use of this type of request features. However, situations $(11,17$ and 19) have the lowest frequency of the study informants' incorrect responses which is an evidence of the positive use of this type of request features.

Situation (8) of the production test with some examples is as follows:

(7) Professor, I am carrying a large number of books. Could you please help me open the door?

(8) Sir, please. I can't open the door. Will you do it for me?

In this situation, the social power of the hearer is higher than that of the speaker and the rank of imposition is also high. In addition, the social distance is there between the interactants. In (7), the student uses an English indirect request strategy 'could you' which is systematically mitigated by the interrogative and the past modal 'could'. The student follows his native culture considering the hierarchical nature of the social relationships where professors have got a remarkable academic and social status in the Arabic society. Consequently, higher levels of indirectness 
should be employed. This is represented by the extra mitigation like the title of hearer, the grounder that precedes the request, the politeness marker 'please' and the literally translated expression 'if possible' (itha mumkin). Likewise, in (8), the student employs an English conventionally indirect request strategy which involves questioning the hearer's willingness in addition to a lot of mitigation devices following his mother culture with regard to speaking with your superiors. The impositive force is downgraded by the address term 'Sir', the politeness marker 'please and the grounder which usually comes before the request whereas the numbers of occurrences of the students' incorrect responses for situations (11, 17 and 19) are (1) making (0.05) each.

An example of students' incorrect responses for item (11) is below:

(9) Could you help me?

In this situation, the interactants have got equal social powers and there is social distance between them. Besides, the imposition is high. The students use an English request strategy (indirect conventional request) which is mitigated syntactically. The speaker does not use any other mitigation because anticipation of help is something normal in Arabic Islamic society. In the Islamic traditions, Muslims should be cooperative towards each other. So, tentative requests are not expected on the part of the hearer and responding to the request is not offensive.

Concerning bilingualism, the total number of informants' incorrect responses is (21) making (1.05\%) which refers to those students who have a negative achievement in this type of request features. They suffer from their L1 interference rather than their L2 culture interference in request production. The situation of the highest occurrence, reflecting the negative use of this type of request features, is situation (8) whereas the lowest ones referring to the positive use of bilingualism are $(2,11,13,14$ and 17). The frequency of the students' incorrect responses for situation (8) is (11) with the percentage (0.55\%). Some examples of the incorrect responses for item (8) are below:

(10) Dr, can you please open the door, dear?

(11) Please, doctor. Can you help me to open the door, dear?

In this situation, the social status of the hearer is higher than the speaker and there is a social distance between the two. Additionally, the impositive force of the request is high. The student produces an Arabic request strategy 'can you' in both examples to ask about the professor's ability to comply with the request. S/he also follows the English individualistic and horizontal culture where less mitigation is used when requesting people with high social status.

On the other hand, the frequency of the students' incorrect responses for situations $(2,11,13,14$ and 17) are (1) making $(0.05 \%)$ each. Situation (2) of the production test says. An example of the incorrect responses for item (2) of the production test is the following;

(12) Sorry, I didn't bring my camera.

In this situation, the interactants' social powers are equal and the imposition is high on the hearer. In addition, the social distance is there between them. The student uses an Arabic request strategy that is even used in English, but it is not desired because it is preferred that the requester should be direct and clear in his request with regard to the English low - context culture. Following the English individualistic culture which seeks to keep its people privacy and maintain their negative faces. The students, therefore, use this strategy so as to reduce the imposition on the hearer's negative face and let him free to comply with the request or to deny it.

\subsubsection{The Male-Female Production of Request}

The total number of female informants' correct responses in the production of request demonstrate a difference between the two sexes with regard to the first type of request features as in Table (8) below:

Table 8. Male-Female Occurrences and percentages of English Monolingualism and Monoculturalism in the Production of Request

\begin{tabular}{|c|c|c|c|c|}
\hline \multicolumn{5}{|c|}{ Correct Responses } \\
\hline English $\mathrm{N}$ & sm and Monoc & & & \\
\hline \multirow[b]{2}{*}{ Item No. } & \multicolumn{2}{|l|}{ Males } & \multicolumn{2}{|l|}{ Females } \\
\hline & Occurrences & $\%$ & Occurrences & $\%$ \\
\hline 1 & 7 & 0.35 & 3 & 0.15 \\
\hline 2 & 10 & 0.5 & 5 & 0.25 \\
\hline 3 & 10 & 0.5 & 8 & 0.2 \\
\hline 4 & 16 & 0.8 & 11 & 0.55 \\
\hline 5 & 7 & 0.35 & 4 & 0.2 \\
\hline
\end{tabular}




\begin{tabular}{|l|l|l|l|l|}
\hline 6 & 6 & 0.3 & 5 & 0.25 \\
\hline 7 & 13 & 0.65 & 2 & 0.1 \\
\hline 8 & 13 & 0.65 & 6 & 0.3 \\
\hline 9 & 6 & 0.3 & 1 & 0.05 \\
\hline 10 & 3 & 0.15 & 8 & 0.4 \\
\hline 11 & 6 & 0.3 & 3 & 0.15 \\
\hline 12 & 21 & 1.05 & 22 & 1.1 \\
\hline 13 & 16 & 0.8 & 6 & 0.3 \\
\hline 14 & 6 & 0.3 & 4 & 0.2 \\
\hline 15 & 0 & 0 & 2 & 0.1 \\
\hline 16 & 4 & 0.2 & 8 & 0.4 \\
\hline 17 & 15 & 0.75 & 6 & 0.3 \\
\hline 18 & 3 & 0.15 & 9 & 0.45 \\
\hline 19 & 4 & 0.2 & 4 & 0.2 \\
\hline 20 & 5 & 0.25 & 7 & 0.35 \\
\hline Total & 171 & 8.55 & 124 & 6.2 \\
\hline & & & & \\
\hline
\end{tabular}

The above table clarifies that males' correct responses (171), which make (8.55), are higher than that females (124) which make (6.2\%). Accordingly, males' positive achievement outperforms that of the females in request production. This refutes hypothesis 5 since males are better than females in request production.

The highest positive occurrence in the male's data exists in item (12) (21) occurrences representing (1.05\%) while their lowest positive occurrence exists in items (10) and (18) of the production test (3) occurrences representing (0.15) each.

Some examples of males data are below:

(13) Could you raise your voice, please?

(14) Would you speak louder, please?

In the above examples, males use English conventional indirect request strategies that are syntactically mitigated by the interrogative and the past modals (could) and (would) in addition to the lexical downgrader (please) showing the nature of the English individualistic culture.

Some examples of item (18) of the production test are as follows:

(15) Can I have a change for 25000 IQ D, please?

(16) Would you give me a change for 25000 IQ D, please?

In Arabic monolingualism and monoculturalism, which is of the highest responses in request production and in the three types of features, the total number of the female informants' incorrect responses is (340), which his higher than that of the male informants which is (318) incorrect responses. Accordingly, females undergo the mother language and culture interference more than males do (see Table 9).

Table 9. Male-Female Occurrences and percentages of Arabic Monolingualism and Monoculturalism in the Production of Request

\begin{tabular}{|c|c|c|c|c|}
\hline \multicolumn{5}{|c|}{ Incorrect Responses } \\
\hline \multicolumn{5}{|c|}{ Arabic Monolingualism and Monoculturalism } \\
\hline \multirow[b]{2}{*}{ Item No. } & \multicolumn{2}{|c|}{ Males } & \multicolumn{2}{|l|}{ Females } \\
\hline & Occurrences & $\%$ & Occurrences & $\%$ \\
\hline 1 & 17 & 0.85 & 20 & 1 \\
\hline 2 & 14 & 0.7 & 18 & 0.9 \\
\hline 3 & 15 & 0.75 & 17 & $\mathbf{0 . 8 5}$ \\
\hline 4 & 7 & 0.35 & 8 & 0.4 \\
\hline 5 & 18 & 0.9 & 21 & 1.05 \\
\hline 6 & 19 & 0.95 & 20 & 1 \\
\hline 7 & 12 & 0.6 & 23 & 1.15 \\
\hline 8 & 7 & 0.35 & 8 & 0.4 \\
\hline
\end{tabular}




\begin{tabular}{|l|l|l|l|l|}
\hline 9 & 19 & 0.95 & 22 & 1.1 \\
\hline 10 & 22 & 1.1 & 15 & 0.75 \\
\hline 11 & 19 & 0.95 & 20 & 1 \\
\hline 12 & 4 & 0.2 & 0 & 0 \\
\hline 13 & 8 & 0.4 & 19 & 0.95 \\
\hline 14 & 19 & 0.95 & 20 & 1 \\
\hline 15 & 25 & 1.25 & 20 & 1 \\
\hline 16 & 21 & 1.05 & 17 & 0.85 \\
\hline 17 & 9 & 0.45 & 18 & 0.9 \\
\hline 18 & 22 & 1.1 & 16 & 0.8 \\
\hline 19 & 21 & 1.05 & 20 & 1 \\
\hline 20 & 20 & 1 & 18 & 0.9 \\
\hline Total & 318 & 15.9 & 340 & 17 \\
\hline
\end{tabular}

The highest negative occurrence, which proves the females Arabic monolingual and monocultural identity in request production, exists in item (7) which has (23) occurrences, (1.15\%) and item (4) and (8) have (8) occurrences, $(0.4 \%)$ each.

The following is some examples about item (7) from the females' data:

(17) Bring me a cup of tea.

(18) I want a cup of tea, please.

In (17), the student uses a direct request strategy without any mitigation in most cases and (18) is a want statement that is literally translated into English. The less use of mitigation represents the hierarchical nature of Arabic society where social power is given more priority than the social distance in Arabic culture.

An example of item (8) of the production test taken from the females' data is as follows:

(19) Excuse me, professor. I am carrying a large number of books and I can't open the door. Can you open the door for me, please?

The example represents the use of Arabic request strategy that is even found in English and the cultural interference through making long-winded request that is excessively mitigated when requesting high-ranking people.

Concerning biculturalism, the results demonstrate a difference between the total number of the male informants' incorrect responses and that of the female informants (Table 10):

Table 10. Male-Female Occurrences and percentages of Biculturalism in Request Production

\begin{tabular}{|c|c|c|c|c|}
\hline Incorrect $\mathrm{F}$ & & & & \\
\hline Biculturali & & & & \\
\hline & Males & & Females & \\
\hline Item No. & Occurrences & $\%$ & Occurrences & $\%$ \\
\hline 1 & 1 & 0.05 & 2 & 0.1 \\
\hline 2 & $\mathbf{0}$ & $\mathbf{0}$ & 2 & 0.1 \\
\hline 3 & 0 & $\mathbf{0}$ & $\mathbf{0}$ & 0 \\
\hline 4 & 2 & 0.1 & 1 & 0.05 \\
\hline 5 & 0 & 0 & 0 & 0 \\
\hline 6 & 0 & $\mathbf{0}$ & $\mathbf{0}$ & $\mathbf{0}$ \\
\hline 7 & 0 & $\mathbf{0}$ & $\mathbf{0}$ & 0 \\
\hline 8 & 2 & 0.1 & 3 & 0.15 \\
\hline 9 & $\mathbf{0}$ & $\mathbf{0}$ & 2 & 0.1 \\
\hline 10 & 0 & $\mathbf{0}$ & 2 & 0.1 \\
\hline 11 & $\mathbf{0}$ & $\mathbf{0}$ & 1 & 0.05 \\
\hline 12 & 0 & $\mathbf{0}$ & 3 & 0.15 \\
\hline 13 & 0 & $\mathbf{0}$ & $\mathbf{0}$ & 0 \\
\hline 14 & $\mathbf{0}$ & $\mathbf{0}$ & $\mathbf{0}$ & $\mathbf{0}$ \\
\hline 15 & 0 & $\mathbf{0}$ & 3 & 0.15 \\
\hline
\end{tabular}




\begin{tabular}{|l|l|l|l|l|}
\hline 16 & 0 & 0 & 0 & 0 \\
\hline 17 & 0 & 0 & 1 & 0.05 \\
\hline 18 & 0 & 0 & 0 & 0 \\
\hline 19 & 0 & 0 & 1 & 0.05 \\
\hline 20 & 0 & 0 & 0 & 0 \\
\hline Total & 5 & 0.25 & 21 & 1.05 \\
\hline
\end{tabular}

The females' incorrect responses (21) which represent (1.05\%) are greater than that of males as (5) incorrect responses which represent $(0.25 \%)$. Females have, therefore, higher negative achievement than males with regard to L1 culture interference. The males' highest negative frequency of incorrect responses exists in items (8), (12) and (15) whereas their lowest positive frequency is in items (4), (11), (17) and (19) of the production test.

The number of occurrences for items (8), (12) and (15) is (3) making (0.15\%) each while that for items (4), (11), (17) and (19) is one occurrence making (0.05) each. Some examples of the females' incorrect responses of item (12) of the are below:

(20) Excuse me, sir. If you allow me, I have some work outside the town. Can I leave early tomorrow, please?

(21) Peace be upon you, sir. Sorry to tell you that I have a lot of work to do outside the town tomorrow. Could I leave early tomorrow if you don't mind?

In the previous examples, the students produce an English indirect request strategies with speaker-oriented perspective with a lot of mitigation devices that are transferred from their use in Arabic culture when requesting superiors, a thing which indicates the hierarchy in Arabic society.

On the other hand, an example of female's incorrect responses of item (4) is:

(22) Peace be upon you, Dr. I have to call my father. If you allow me, can I use your phone? I really need it, please.

The student employs an English indirect request strategy with a lot of mitigation devices such as Islamic salutation, the hearer' title, the conditional clause, the politeness marker and the grounder to soften the imposition on the lecturer, who has a high status in Arabic culture.

With reference to bilingualism use, the male informants' incorrect responses are (6) ones making $(0.3 \%)$ whereas those of females are (15) ones making $(0.75 \%)$. Hence, the females have much tendency to transfer their L1 request strategies than males do (see Table 11).

Table 11. Male-Female Occurrences and percentages of Bilingualism in Request Production

\begin{tabular}{|c|c|c|c|c|}
\hline \multicolumn{5}{|c|}{ Incorrect Responses } \\
\hline \multicolumn{5}{|c|}{ Bilingualism } \\
\hline \multirow[t]{2}{*}{ Item No. } & \multicolumn{2}{|l|}{ Males } & \multicolumn{2}{|l|}{ Females } \\
\hline & Occurrences & $\%$ & Occurrences & $\%$ \\
\hline 1 & $\mathbf{0}$ & $\mathbf{0}$ & $\mathbf{0}$ & $\mathbf{0}$ \\
\hline 2 & 1 & 0.05 & $\mathbf{0}$ & $\mathbf{0}$ \\
\hline 3 & $\mathbf{0}$ & $\mathbf{0}$ & $\mathbf{0}$ & $\mathbf{0}$ \\
\hline 4 & $\mathbf{0}$ & $\mathbf{0}$ & 5 & 0.25 \\
\hline 5 & $\mathbf{0}$ & $\mathbf{0}$ & $\mathbf{0}$ & $\mathbf{0}$ \\
\hline 6 & $\mathbf{0}$ & $\mathbf{0}$ & $\mathbf{0}$ & $\mathbf{0}$ \\
\hline 7 & $\mathbf{0}$ & $\mathbf{0}$ & $\overline{\mathbf{0}}$ & $\mathbf{0}$ \\
\hline 8 & 3 & 0.15 & 8 & 0.4 \\
\hline 9 & $\mathbf{0}$ & $\mathbf{0}$ & $\overline{\mathbf{0}}$ & $\mathbf{0}$ \\
\hline 10 & $\mathbf{0}$ & $\mathbf{0}$ & $\mathbf{0}$ & $\mathbf{0}$ \\
\hline 11 & $\mathbf{0}$ & $\mathbf{0}$ & 1 & 0.05 \\
\hline 12 & $\mathbf{0}$ & $\mathbf{0}$ & $\overline{\mathbf{0}}$ & $\mathbf{0}$ \\
\hline 13 & 1 & 0.05 & $\mathbf{0}$ & $\mathbf{0}$ \\
\hline 14 & $\mathbf{0}$ & $\mathbf{0}$ & 1 & 0.05 \\
\hline 15 & $\mathbf{0}$ & $\mathbf{0}$ & $\mathbf{0}$ & $\mathbf{0}$ \\
\hline 16 & $\mathbf{0}$ & $\mathbf{0}$ & $\mathbf{0}$ & $\mathbf{0}$ \\
\hline 17 & 1 & 0.05 & $\mathbf{0}$ & $\mathbf{0}$ \\
\hline
\end{tabular}




\begin{tabular}{|l|l|l|l|l|}
\hline 18 & 0 & 0 & 0 & 0 \\
\hline 19 & 0 & 0 & 0 & 0 \\
\hline 20 & 0 & 0 & 0 & 0 \\
\hline Total & 6 & 0.3 & 15 & 0.75 \\
\hline
\end{tabular}

The highest negative occurrence of females' incorrect responses in the use of bilingualism is in item (8) which has (8) occurrences; (0.4\%). However, items (11) and (14) have (1) occurrence with the percentage of $(0.05 \%)$ each. The following is item (14) with an example from the female's data:

(23) Excuse me, sir. Move you head a little bit, please. I can't see the screen.

The student employs an Arabic request strategy which indicates solidarity and does not need to be so mitigated in Arabic collectivist culture. However, the student's use of extra mitigating devices exhibits the individualistic cultural traits to maintain one's negative face especially when there is a social distance between the interactants.

\subsection{Comparison}

This section involves comparison of the students' recognition and production regarding the four types of request features, comparison of the students' recognition and production and comparison between males and females regarding the four types of request features.

\subsubsection{Comparison of the Students' Recognition and Production of Request}

The results of the recognition and production test state that the number of students who have English monolingualism and monocultural identity in request perception and production is too little in comparison with those who have bilingual, bicultural or Arabic monolingual and monocultural identities altogether ( Table 12):

Table 12. Occurrences of the Students' Recognition and Production of the Four Types of Request Features

\begin{tabular}{|c|c|c|c|c|c|c|c|c|}
\hline \multirow{3}{*}{$\begin{array}{l}\text { Item } \\
\text { No. }\end{array}$} & \multirow{2}{*}{\multicolumn{2}{|c|}{$\begin{array}{c}\text { Correct Responses } \\
\text { English } \\
\text { Monolingualism and } \\
\text { Monoculturalism } \\
\end{array}$}} & \multicolumn{6}{|c|}{ Incorrect Responses } \\
\hline & & & \multicolumn{2}{|c|}{ Biculturalism } & \multicolumn{2}{|c|}{ Bilingualism } & \multicolumn{2}{|c|}{$\begin{array}{l}\text { Arabic Monolingualism } \\
\text { and Monoculturalism }\end{array}$} \\
\hline & 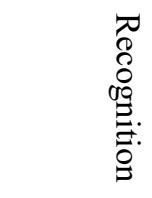 & $\begin{array}{l}\text { 유. } \\
\stackrel{0}{0} \\
\text { ڤ. }\end{array}$ & 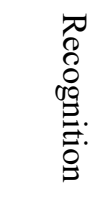 & 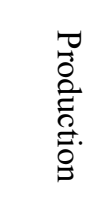 & 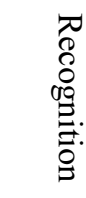 & 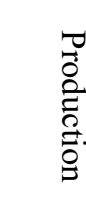 & 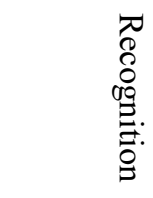 & 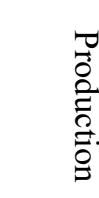 \\
\hline 1 & 48 & 19 & 12 & 15 & 22 & 0 & 18 & 76 \\
\hline 2 & 16 & 30 & 18 & 3 & 20 & 1 & 46 & 66 \\
\hline 3 & 51 & 31 & 11 & 0 & 15 & 0 & 23 & 69 \\
\hline 4 & 15 & 55 & 43 & 5 & 20 & 6 & 22 & 34 \\
\hline 5 & 28 & 16 & 32 & 0 & 14 & 1 & 26 & 83 \\
\hline 6 & 20 & 24 & 27 & 0 & 23 & 0 & 30 & 76 \\
\hline 7 & 27 & 31 & 23 & 0 & 18 & 0 & 32 & 69 \\
\hline 8 & 30 & 43 & 25 & 6 & 7 & 15 & 38 & 36 \\
\hline 9 & 21 & 20 & 14 & 2 & 17 & 1 & 48 & 77 \\
\hline 10 & 15 & 23 & 30 & 2 & 18 & 0 & 37 & 75 \\
\hline 11 & 45 & 21 & 12 & 1 & 9 & 1 & 34 & 77 \\
\hline 12 & 20 & 83 & 18 & 5 & 42 & 0 & 20 & 12 \\
\hline 13 & 31 & 51 & 31 & 0 & 10 & 1 & 28 & 48 \\
\hline 14 & 31 & 18 & 16 & 0 & 16 & 1 & 37 & 81 \\
\hline 15 & 22 & 10 & 23 & 3 & 18 & 0 & 37 & 87 \\
\hline 16 & 31 & 23 & 22 & 0 & 4 & 1 & 43 & 76 \\
\hline 17 & 26 & 59 & 16 & 2 & 25 & 1 & 33 & 38 \\
\hline 18 & 10 & 17 & 20 & 0 & 36 & 0 & 34 & 83 \\
\hline 19 & 14 & 18 & 18 & 1 & 31 & 0 & 37 & 81 \\
\hline 20 & 18 & 30 & 18 & 0 & 37 & 0 & 27 & 70 \\
\hline
\end{tabular}




\begin{tabular}{l|l|l|l|l|l|l|l|l|} 
Total & 519 & 622 & 429 & 35 & 402 & 29 & 650 & 1314 \\
\hline
\end{tabular}

What is mentioned above is clearly demonstrated if a comparison is made between the number of the correct responses in the recognition and production test parts as (519) and (622) correct responses making (25.95\%) and (31.1\%) respectively with the incorrect responses together making $(74.05 \%)$ and $(68.9 \%)$ respectively. Thus, hypothesis 6 is refuted because students' positive request production is better than their recognition one. Accordingly, a good number of students have an English monolingual and monocultural identity through the responses they made in the two test parts that follow the English request strategies and the English individualistic cultural traits. Hence, the first research questions (What are the linguistic patterns of request in English?) and (To what extent are students better in English monolingualism and monoculturalism than in the other three types of request features?) are responded to.

Furthermore, hypothesis 7 (Students are better in English monolingualism and monoculturalism than in the other three types of request features in both recognition and production) is refuted and it can be definitely stated that students have less adequate performance in English monolingualism and monoculturalism in comparison with the other three types of request features that refer to their inadequate performance.

On the other hand, the majority of students have a language interference, a culture interference or a language and culture interferences in using request, a thing that is proven through the choices they made in the recognition test and the sentences they formed in the production test. Thus, hypothesis $\mathbf{8}$ is accepted. There is bilingual and bicultural identity in using request by Iraqi EFL learners in both recognition and production. Their choices and sentences involve the Arabic linguistic and cultural patterns that are negatively transferred into English.

Likewise, and as a result, these findings answer the third, fourth and fifth research questions. These findings also achieve the aims of the study that are as follows:

1. Exploring the linguistic patterns of request in English.

2. Exploring the linguistic realization of request used by Iraqi EFL learners.

3. Identifying the linguistic patterns of request which are transferred from Iraqi EFL learners' mother tongue in the EFL.

4. Exploring the Iraqi EFL learners' cultural patterns of request.

5. Exploring the cultural realization of request transferred from Arabic culture into the EFL.

Furthermore, the students, who have an English monolingual and monocultural identity in request production, outperform those in the recognition test as they make (622) correct responses in production compared to (514) in recognition. This finding answers the research question (To what extent is the students' English monolingual and monocultural identity more apparent in request perception or in request production?) and it refutes hypothesis 9 (students' English monolingual and monocultural identity is more apparent in request perception than in production). Thus, it is obvious that students' English monolingual and monocultural identity is more apparent in request production than in request perception.

However, the students who have an Arabic monolingual and monocultural identity exceed those who have a bilingual or a bicultural identity in the recognition and production tests. It can be stated that students' Arabic monolingual and monocultural identity is the most dominant among the other three types of request features in request recognition and production. The same result answers the research question which says : (To what extent are students better in English monolingualism and monoculturalism than in the other three types of request features?)

The Arabic monolingual and monocultural identity is the most prevalent identity in both test parts, but it is extremely greater in the production test than in the recognition test as (1314), (650) incorrect responses respectively. This may be because students can understand a lot with little knowledge of language when perceiving request. Producing request, on the other hand, requires knowing and using the sociopragmatic rules of language, its structure, vocabulary, word order, etc. The production of appropriate requests needs a linguistic expertise in addition to exposure to the FL culture. This can be achieved when students are given the opportunities to practise the speech acts depending on the materials that involve an appropriate input to boost their pragmatic awareness in an explicit way. Hence, the use of L1 request strategies and L1 culture traits are expected to be less. 


\subsubsection{Comparison of Male-Female Students' Recognition and Production of Request}

Data analysis of male and female informants states that male and female informants' negative achievement exceeds their positive achievement in the recognition and production levels. Males' correct responses are (263) as opposed to (737) incorrect responses in the other three types of request features and (358) correct responses as opposed to (642) incorrect responses in the recognition and production tests respectively. On the other hand, females' correct responses are (256) as opposed to (744) incorrect responses and (263) as opposed to (337) incorrect responses in the recognition and production tests respectively (Table 13):

Table 13. Male-Female Students' Recognition Production of the Four Types of Request

\begin{tabular}{|c|c|c|c|c|c|c|c|c|c|c|c|c|c|c|c|c|}
\hline \multirow{4}{*}{$\begin{array}{l}\text { Item } \\
\text { No. }\end{array}$} & \multirow{2}{*}{\multicolumn{4}{|c|}{$\begin{array}{c}\text { Correct Responses } \\
\text { English } \\
\text { Monolingualism and } \\
\text { Monoculturalism }\end{array}$}} & \multicolumn{12}{|c|}{ Incorrect Responses } \\
\hline & & & & & \multicolumn{4}{|c|}{ Biculturalism } & \multicolumn{4}{|c|}{ Bilingualism } & \multicolumn{4}{|c|}{$\begin{array}{l}\text { Arabic Monolingualism } \\
\text { and Monoculturalism }\end{array}$} \\
\hline & \multicolumn{2}{|c|}{ 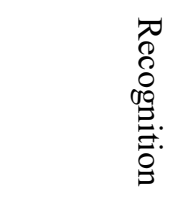 } & \multicolumn{2}{|r|}{ 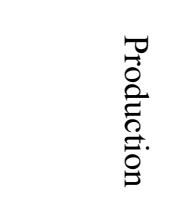 } & \multicolumn{2}{|c|}{ 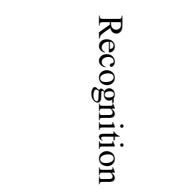 } & \multicolumn{2}{|r|}{ 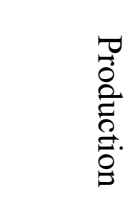 } & \multicolumn{2}{|r|}{ 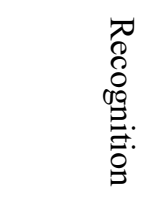 } & \multicolumn{2}{|r|}{ 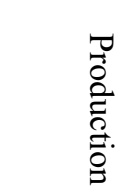 } & \multicolumn{2}{|r|}{ 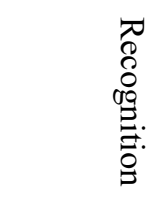 } & \multicolumn{2}{|r|}{ 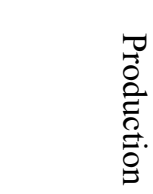 } \\
\hline & $\frac{3}{2}$ & $\begin{array}{l}1 \\
3_{0}^{2} \\
\stackrel{8}{8}\end{array}$ & $\frac{3}{8}$ & 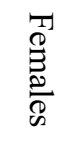 & $\frac{3}{2}$ & $\begin{array}{l}T \\
0 \\
\stackrel{2}{0} \\
\stackrel{0}{8} \\
\infty\end{array}$ & $\frac{3}{\infty}$ & $\begin{array}{l}T \\
0 \\
0 \\
0 \\
0 \\
0 \\
0\end{array}$ & $\frac{3}{\stackrel{2}{\infty}}$ & 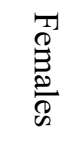 & $\begin{array}{l}3 \\
\frac{3}{0} \\
\stackrel{0}{8}\end{array}$ & $\begin{array}{l}T \\
9 \\
\stackrel{2}{2} \\
\stackrel{0}{0} \\
\infty\end{array}$ & $\frac{3}{\mathbb{2}}$ & 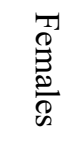 & $\begin{array}{l}3 \\
\frac{0}{0} \\
\frac{0}{2}\end{array}$ & 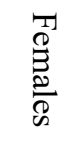 \\
\hline 1 & 27 & 21 & 12 & 7 & 5 & 7 & 3 & 2 & 10 & 12 & 0 & 0 & 8 & 10 & 35 & 41 \\
\hline 2 & 6 & 10 & 18 & 12 & 8 & 10 & 1 & 2 & 9 & 11 & 1 & 0 & 27 & 19 & 30 & 36 \\
\hline 3 & 28 & 23 & 18 & 13 & 3 & 8 & 0 & 0 & 9 & 6 & 0 & 0 & 10 & 13 & 32 & 37 \\
\hline 4 & 7 & 8 & 30 & 24 & 26 & 17 & 3 & 3 & 7 & 13 & 0 & 6 & 10 & 12 & 17 & 17 \\
\hline 5 & 14 & 14 & 8 & 8 & 15 & 17 & 0 & 0 & 8 & 6 & 1 & 0 & 13 & 13 & 41 & 42 \\
\hline 6 & 6 & 14 & 14 & 10 & 17 & 10 & 0 & 0 & 13 & 10 & 0 & 0 & 14 & 16 & 36 & 40 \\
\hline 7 & 12 & 15 & 22 & 9 & 14 & 9 & 0 & 0 & 11 & 7 & 0 & 0 & 13 & 19 & 28 & 41 \\
\hline 8 & 17 & 13 & 26 & 17 & 11 & 14 & 2 & 4 & 3 & 4 & 3 & 12 & 19 & 19 & 19 & 17 \\
\hline 9 & 11 & 10 & 16 & 4 & 6 & 8 & 0 & 2 & 10 & 7 & 0 & 1 & 23 & 25 & 34 & 43 \\
\hline 10 & 10 & 5 & 10 & 13 & 12 & 18 & 0 & 2 & 9 & 9 & 0 & 0 & 19 & 18 & 40 & 35 \\
\hline 11 & 20 & 25 & 12 & 9 & 9 & 3 & 0 & 1 & 4 & 5 & 0 & 1 & 17 & 17 & 38 & 39 \\
\hline 12 & 8 & 12 & 44 & 39 & 10 & 8 & 1 & 4 & 24 & 18 & 0 & 0 & 8 & 12 & 5 & 7 \\
\hline 13 & 15 & 16 & 32 & 19 & 16 & 15 & 0 & 0 & 7 & 3 & 1 & 0 & 12 & 16 & 17 & 31 \\
\hline 14 & 17 & 14 & 13 & 5 & 12 & 4 & 0 & 0 & 6 & 10 & 0 & 1 & 15 & 22 & 37 & 44 \\
\hline 15 & 11 & 11 & 6 & 4 & 10 & 13 & 0 & 3 & 9 & 9 & 0 & 0 & 20 & 17 & 44 & 43 \\
\hline 16 & 14 & 17 & 11 & 12 & 13 & 9 & 0 & 0 & 2 & 2 & 0 & 1 & 21 & 22 & 39 & 37 \\
\hline 17 & 17 & 9 & 34 & 25 & 10 & 6 & 0 & 2 & 8 & 17 & 1 & 0 & 15 & 18 & 15 & 23 \\
\hline 18 & 5 & 5 & 7 & 10 & 8 & 12 & 0 & 0 & 17 & 19 & 0 & 0 & 20 & 14 & 43 & 40 \\
\hline 19 & 10 & 4 & 9 & 9 & 9 & 9 & 0 & 1 & 14 & 17 & 0 & 0 & 17 & 20 & 41 & 40 \\
\hline 20 & 8 & 10 & 16 & 14 & 15 & 3 & 0 & 0 & 17 & 20 & 0 & 0 & 10 & 17 & 34 & 36 \\
\hline Total & 263 & 256 & 358 & 263 & 229 & 200 & 10 & 26 & 197 & 205 & 7 & 22 & 311 & 339 & 625 & 689 \\
\hline
\end{tabular}

As clear from the above table, the previous numbers demonstrate that males are more pragmatically competent than females on the pragmalinguistic and sociopragmatic levels in the recognition and production of request.

In recognition test, males' utilization of biculturalism, bilingualism and Arabic monolingualism and monoculturalism represents (229), (197) and (311) incorrect responses respectively. However, females' use of the aforementioned types of request features represents (200), (205) and (339) respectively. Consequently, males are more subject to bicultural interference than females who are more subject to the bilingual interference in request perception.

In the production test, males' employment of biculturalism, bilingualism and Arabic monolingualism and monoculturalism makes (10), (7) and (625) incorrect responses respectively. Yet, females' use of the 
aforementioned types makes (26), (22) and (689) respectively. Thus, one main point is concluded that mother tongue interference and mother culture interference are highly recorded in females than in males in request production. Another point is that females exhibit more tendencies towards the use of their mother tongue request strategies and their cultural traits altogether than males do in request recognition and production. This is definitely clear in their use of Arabic monolingualism and monoculturalism in which the choices they made and the sentences they formed implied the Arabic linguistic and cultural patterns as the pervasive ones. As a result, the discussion above refutes the hypothesis (10): (Females are better than males in Arabic monolingualism and monoculturalism) and it is, therefore, substituted for (males are better than females in Arabic monolingualism and monoculturalism). The twelfth research question (How are males and males different in Arabic monolingualism and monoculturalism use?) is answered. The above findings also achieve the first two hypotheses; that is, there is a bilingual identity and a bicultural identity in using requests by Iraqi EFL learners and they answer the first four research questions that are previously mentioned.

Generally, students are pragmatically incompetent in request perception and production due to the idea that the incorrect responses are much higher than their incorrect ones in both test parts. There are many reasons for such deficiency like the lack of pragmatic competence that cannot be activated in the FL context without the materials that are dedicated to enhance pragmatic competence. Most of textbooks at the university level focus only on grammatical competence and there is insufficient training about the English culture. Also, there are cross-cultural differences between English and Arabic that must be highlighted in order to be noticed by the students to save them committing sociopragmatic errors even if the materials focus on the pragmalinguistic knowledge of request or any other speech act.

Further, most students are not aware of the context and they, thus, resort to literal translation of their requests in Arabic that represent deviations from the pragmalinguistic and sociopragmatic norms of English. Another reason is that speech acts are not given a considerable space in the university syllabus. Also, it is worth mentioning that the lack of interaction and cooperation is another reason for the students' pragmatic failure in making requests where the classroom communication is the only way to practise requesting in FL context. Furthermore, pandemic condition also leads to the aforementioned reason.

\section{Conclusions}

On the basis of the results outlined in section 4, the researcher arrives at the following conclusions:

1. The gender factor affects the Iraqi EFL learners' bilingual and bicultural identity in the recognition and production of request for the following reasons:

a. Females outperform males concerning positive achievement in request perception.

b. Iraqi EFL learners are pragmatically incompetent since their negative achievement is higher than their positive one in request perception and production. The same is true if the sex factor is taken into consideration.

c. There is a difference between males and females. Through their negative achievement represented by their incorrect choices. Males' achievement is higher than that of females.

d. In Arabic monolingualism and monoculturalism, the female informants' incorrect responses are higher than those of the male ones. Accordingly, females undergo the mother language and culture interference more than males do.

e. Females have, therefore, higher negative achievement than males with regard to L1 culture interference.

f. Male and female informants' negative achievement exceeds their positive achievement in the recognition and production levels.

2. Iraqi EFL Learners have a bilingual and bicultural identity in performing request because of their mother tongue, and their mother culture interference or both of them in request perception and production.

3. Generally, the data shows that males are better than females in request perception and production.

4. In general, males are more subject to bicultural interference than females who are more subject to the bilingual interference in request recognition whereas males have less use of the previously mentioned types of request features in request production. Also, one main point is concluded that mother tongue and mother culture interference together highly recorded in females requestive behavior than in males in the recognition and production of request.

5. Students have less performance in English monolingualism and monoculturalism in comparison with the other negative types of request features that demonstrate their inadequate performance. This is also confirmed 
in the male and female students in the recognition and production levels. This is related to many reasons, among which are the following:

a. The Iraqi EFL learners have difficulty in utilizing the conversational maxims when they are required to fulfill all the maxims. They breach up all the maxims of conversation when they are exposed to situations from real life in relatively different degrees (Betti and Yaseen, 2020: 58).

b. Iraqi EFL learners encounter difficulties in the production of SAs because of their lack of pragmatic competence; that is, they are not well-informed of where and when to use SAs appropriately (Betti and Hasan, 2020: 41-42) .

c. The teaching of composition writing using Estafet technique has a major influence on the growth of the overall ability of fifth-year Preparatory School students (Dehham, Betti and Hussein, 2021: 10). In this regard, "there should be an emphasis on the study of collocated words in teaching English because this will lead the students to use the language appropriately like native speakers" (Igaab \& Abdulhasan, 2018, p. 100). In this regard, "cohesion is divided in English into grammatical, lexico-grammatical and lexical" (Ibid, Igaab, \& Abdulhasan, 2018, p. 100).

Likewise, the use of pronouns and concord is very important. First, "there is a difficulty in describing pronouns syntactically, semantically and pragmatically in Arabic because the types of pronouns which are dealt with syntactically are different from those which are dealt with semantically and pragmatically" (Igaab and Tarrad, 2019, p. 53) 7. Students' English monolingual and monocultural identity is more apparent request perception than in request production since receptive skills are easier than productive ones.

Participants of any talkative activity may encounter frequent occurrences of "disfluencies" e.g., "umms", "ahhs", "hesitation markers", "misarticulations", exploitation of "a wrong word", inaccessibility to a word if looked-for, "failure to hear or to be heard", and inappropriate understandings by receivers, or some other talk troubles, etc. (Sert, 2015, pp. 88-89; Betti and Mahdi, 2021: 15). Thus, the teacher may preserve any errors alike to phonological, syntactical, or pragmatic misuse as trouble and thus such repairable must be repaired (Betti and Mahdi, 2020: 72).

6. The Arabic monolingual and monocultural identity is the most negative prevailing one among the other three identities in request perception and production. This identity which represents the transfer of the Arabic linguistic and cultural patterns is the main identity among the Iraqi EFL learners, males or females.

7. The scale on which the degree of the mother tongue and culture interference measured shows that students have a total linguistic and cultural interference represented by Arabic monolingualism and monoculturalism use followed by bilingualism and biculturalism use in request perception. In request production, students use Arabic monolingualism and monoculturalism followed by biculturalism and bilingualism. They, in turn, go back to their direct Arabic request strategies evaluated by their collectivist, Islamic hierarchical culture.

8 . The students' data reveals that females are more pragmatically competent than males in request perception whereas the reverse is true in request production. Regarding their negative achievement, females make more positive use of biculturalism and Arabic monolingualism and monoculturalism whereas they have more negative use of bilingualism than males do in request perception. On the other hand, males have more positive use of biculturalism, bilingualism and Arabic monolingualism and monoculturalism in request production.

9. English request strategies, that are employed by Iraqi EFL learners, are confined to the query preparatory like 'Can you', 'Could you' and 'Would you' in some cases in addition to the speaker - oriented perspective, e.g., 'Can I' and 'May I' in some sentences. This demonstrates their limited linguistic expertise that does not match the native sophisticated one.

10. The most predominant Arabic request strategies that are transferred from the Iraqi EFL learners' native language are 'the bare imperative', 'the query preparatory/ Can you' and the literally translated want statement from Arabic in rare cases. Request mitigation devices such as the politeness marker 'please', apology 'sorry/excuse me', vocatives, Islamic greeting 'peace be upon you' and the excessive use of grounders are also negatively transferred into English with a very simple language that also refers to the poor level of their linguistic and pragmatic knowledge.

11. Iraqi EFL learners cannot overcome their L1 culture interference since they assess the social and contextual variables in every situation they encountered in terms of their collectivist Islamic culture and the hierarchical nature of their Arabic society. This is actually proven through showing higher levels of indirectness when requesting their superiors, for example, and higher levels of directness when requesting their inferiors influenced by their hierarchical culture. Moreover, directness is also spotted in their requestive behaviour with familiars and non-familiars since cooperativeness on the part of the previously mentioned people is anticipated as part of the Islamic traditions. 
12. The lack of pragmatic competence prompts Iraqi EFL learners literal translation of their L1 request strategies transferring them into the EFL on the pragmalinguistic competence. In addition, their unawareness of the cross-cultural differences between Arabic and English negatively stimulates them to transfer their L1 culture characteristics and its elements.

\section{References}

Abdul Sattar, A. Lah, S., \& Suleiman, R. (2009). Iraqi Postgraduates' Production and perception of requests: A Pilot Study. The International Journal of Language, Society and Culture, 29, 56-70.

Abdul-Sattar, H. Q. and Farnia, M. (2014). A Cross-Cultural Study of Request Speech Act: Iraqi and Malay Students. Applied Research on English Language, 3(2), 35-54.

Al-Ageel, H. (2016). Requesting Behaviour of Saudi Arabian Woman in Contemporary Arabic-Speaking Situations. MA Thesis. Melbourne: La Trobe University.

Al-Ali, M and Alawneh, R. (2010). Linguistic Mitigating Devices in American and Jordanian Students' Requests. Intercultural Pragmatics, 2(7), 311-339. https://doi.org/10.1515/iprg.2010.014

Al-Badawi, K. (2012). An Analysis of Phonetic, Morphological and Syntactic Errors in English: A case Study of Saudi BA students at King Khalid University. International Journal of Social Science and Humanity, 2(6). 536-538. https://doi.org/10.7763/IJSSH.2012.V2.165

Aldulaee, M. T. (2011). Request Mitigating Devices in Australian English and Iraqi Arabic: A Comparative Study. MA Thesis. Deakin; Deakin University.

Ali, N. (2007). Some Linguistic Problems Facing Arab Learners of English. ADAB AL-RAFIDAYN, 48, 117-130.

Alkhateeb, M. M. A. (2016). My Mother Tongue Pulls my Leg Arabic Language Interference in the Acquisition of English Language: An Attempt to Know How. Journal of Education and Practice, 7(23), 96-102.

Al-Otaibi, S. M. (2015). Saudi EFL Students' Knowledge in Pragmatics-Making Requests. Arab World English Journal (AWEJ), 6(2), 303-315. https://doi.org/10.24093/awej/vol6no2.23

Al-Seady, Mohammed J. B. (1998a). Comparative Education: Some Basic Contributions of Islamic Education to Western Educational Thought. Al- Qadisiya Journal, 3(2), 82-89.

Al-Seady, Mohammed J. (1998b). Teaching EFL Vocabulary. Al-Qadisiya Journal, 3(2), 59-69.

Al-Seady, Mohammed J. B. (1998c). The Employment of English Lexicons by Adolescent Speakers of Nasiriya Iraqi Arabic as Determined by Sex Differentiation. Al-Qadisiya Journal, 3(2), 72-79.

Al-Seady, Mohammed J. B. (2002). Some Morphological, Lexical and Syntactic Aspects of the Interlanguage of Third Year Students/ Dept. of English / College of Education/ University of Qadisiya. Journal of Qadisiya for Educational Sciences, 2(1), 13-19.

Al-Sheikh, Z. K. (2006a). Iraqi EFL Performance in using evidentiality. Journal of University of Thi-Qar, 2(3), 68-86.

Al-Sheikh, Z. K. (2006b). The Ability of Iraqi Undergraduates to Recognize and Produce Confusing Words in English. Journal of University of Thi-Qar, 2(3), 68-85.

Al Zumor, A. (2012). A Pragmatic Analysis of Speech Acts as Produced by Arab ESL Learners. Saarbrücken: LAP LAMBERT Academic Publishing.

Anderson, L. (2019). Philosophical Investigations of the Taboo of Insult. In K. Allan (ed.), The Handbook of Taboo Words and Language (PP. 230-249). Oxford: Oxford University Press. https://doi.org/10.1093/oxfordhb/9780198808190.013.13

Aziz, Y. Y. (1989). A Contrastive Grammar of English and Arabic. Mosul: University of Mosul.

Azzouz, A. (2013). "Interference of Syntactic, Lexical and Phonological Aspects from Arabic into English for Syrian University Students: A Cross-Sectional Study in HIL at Allepo University". Ph. D. Dissertation. Allepo: Allepo University.

Betti, Mohammed J. (1990). Teaching English Drama for Educational Purposes in the Iraqi Colleges of Education with Reference to the Universities of Basrah, Baghdad and Mosul. Basrah: University of Basrah.

Betti, Mohammed Jasim. (1993). English for Literary Purposes (ELP): A Case Study. Published in the literature of The Conference of Applied Studies in Linguistics and Poetics. University of Mosul.

Betti, M. J., \& Al Juboury, G. F. (2015). Approaches and Methods of Teaching English as a Foreign Language. 
Diwaniya: Nippur Publishing.

Betti, Mohammed Jasim and Ulaiwi, W. A. (2018). Stress in English and Arabic: A Contrastive Study. English Language and Literature Studies, 8(1), 83-91. https://doi.org/10.5539/ells.v8n1p83

Betti, Mohammed Jasim and Igaab, Zainab Kadim (2019). Sound Shift and Metathesis in Three Pre-School Nasiriya Iraqi Arabic Children: A Case Study. International Journal of English Linguistics, 9(1), 229-240. https://doi.org/10.5539/ijel.v9n1p229

Betti, Mohammed J., \& Hasan, A. A. (2020). The Iraqi EFL Learners' Ability to Use Speech Acts in MA and Ph.D. Theses Defense. Education, Language and Sociology Research, 1(2), 41-65. https://doi.org/10.22158/elsr.v1n2p41

Betti, Mohammed J., \& Mahdi, Mohammed A. (2020). A Conversation Analysis of Repair Trouble Sources, Inadequacy and Positions in the Iraqi University Viva Discussions in English. International Linguistics Research, 3(4), 69-93. https://doi.org/10.30560/ilr.v3n4p69

Betti, Mohammed J., \& Yaseen, K. S. (2020). The Iraqi EFL Learners' Use of Conversational Maxims at the University Level. Education, Language and Sociology Research, 1(1), 43-60. https://doi.org/10.22158/elsr.v1n1p43

Betti, Mohammed J., \& Mahdi, Mohammed A. (2021). A Conversation Analysis of Staff Members' and Researchers' Repair Strategies in the Iraqi University Viva Discussions in English. Education, Language and Sociology Research, 2(1), 14-56.

Blum-Kulka, S., \& Olshtain, E. (1984). Requests and Apologies: A cross-Cultural Study of Speech Act Realization Patterns (CCSARP). Applied Linguistics, 5(3), 196-213. https://doi.org/10.1093/applin/5.3.196

Blum-Kulka, S. House, J., \& Kasper, G. (1989). Cross-Cultural Pragmatics: Requests and Apologies. Norwood, NJ: Ablex.

Briner, B. J. (2013). Introduction to Pragmatics. Malden, MA: Wiley Blackwell. https://doi.org/10.7202/1017210ar

Brown, P., \& Levinson, S. (1987). Politeness: Some Universals in Language Usage. Cambridge: Cambridge University Press. https://doi.org/10.1017/CBO9780511813085

Byon, A. S. (2004). Sociopragmatic Analysis of Korean Requests. Pedagogical Journal of Pragmatics, 36(9), 1673-1704. https://doi.org/10.1016/j.pragma.2004.05.003

Carroll, D. W. (2008). Psychology of Language ( th $^{\text {edn. }}$ ). Belmont: Thomson Wordsworth.

Chen, C. (2020). A Study on Positive Transfer of Native Lnguage and Second Language Teaching Methods. Theory and Practice in Language Studies, 10(3), 306-312. https://doi.org/10.17507/tpls.1003.06

Daskalovska, N., Ivanovska, B., Kusevska, M., \& Ulanska, T. (2016). The Use of Request Strategies by EFL Learners. Procedia-social and behavioral Sciences, 232, 55-61. https://doi.org/10.1016/j.sbspro.2016.10.015

DeCapua, A., \& Wintergerst A. C. (2016). Crossing cultures in the language Classroom ( $2^{\text {nd }}$ edn.). Michigan: University of Michigan Press. https://doi.org/10.3998/mpub.7367950

Dehham, S. H., Betti, Mohammed J., \& Hussein, N. M. (2021). The Effect of Using Estafet Writing Technique to Enhance Students' Compositional Efficiency. Education, Language and Sociology Research, 2(1), 1-13.

Dendenne, B. (2014). Could you help me with these bags brother? My shoulders are falling. Transfer in Interlanguage Requests Performed by Algerian EFL Learners. Journal of Language and Linguistic Studies, 10 (2), 29-47.

Fetzer, A. (2004). Recontextualizing Context. Amesterdam: John Benjamins Publishing Company. https://doi.org/10.1075/pbns.121

Fetzer, A. (2007). Context and Appropriateness. Amesterdam: John Benjamins Publishing Company. https://doi.org/10.1075/pbns.162

Geis, M. G., \& Harlow, L. (1996). Politeness Strategies in French and English”. In S. M. Gass and J. Neu (eds.), Speech Acts Across Cultures: Challenge to Communication in a Second Language (pp. 129-154). Berlin: Mouton de Gruyter. https://doi.org/10.1515/9783110219289.2.129

Ghazzoul, N. (2019). Linguistic and Pragmatic Failure of Arabic Learners in Direct Polite Requests and Invitations: Across-cultural Study. Theory and Practice in Language Studies, 9(2), 223-230. 
https://doi.org/10.17507/tpls.0902.13

Hamers, J. F., \& Blank, H. A. (2004). Bilinguality and Bilingualism ( ${ }^{\text {nd }}$ edn.). Cambridge: Cambridge University Press.

Hammadi, S. S. (2019). An Inter-language Pragmatic Study of Request Acts by Iraqi and Turkish EFL Learners: A Comparative Study. Midad Al-Adab Refreed Journal, 1(17), 823-844.

Igaab, Z. K. (2010a) Reduplication in English and Arabic: A Contrastive Study. Journals Education for Girls, 1(1), 3-24.

Igaab, Z. K. (2010b). A Contrastive Study of Metathesis in English and Arabic. Wasit: Journal of College of Education, 1(7), 152-172.

Igaab, Z. K., \& Abdulhasan, H. (2018). Collocation in English and Arabic: A Contrastive Study. English Language and Literature Studies, 8(4), 89-103. https://doi.org/10.5539/ells.v8n4p89

Igaab, Z. K., \& Tarrad, I. R. (2019). Pronouns in English and Arabic: A Contrastive Study. English Language and Literature Studies, 9(1), 53-69. https://doi.org/10.5539/ells.v9n1p53

James, C. (1998). Errors in Language Learning and Use: Exploring Error Analysis. London: Routledge.

Khalil, A (1981). Areas of Difficulty for Arab Learners of English. Bethlehem University Journal, 1(1), 23-29

Kasper, G. (1992). Pragmatic Transfer. University of Hawaii working Papers in ESL, 11(1), 1-34. https://doi.org/10.1177/026765839200800303

Khatab, M. K. (2015). A socio-Pragmatic Study of Request Modification in Iraqi Non-Standard Arabic. Midad Al. Adab Refereed Journal, 1(11), 683-706.

Leech, G. (2014). The Pragmatics of Politeness. Oxford: Oxford University Press. https://doi.org/10.1093/acprof:oso/9780195341386.001.0001

Liu, D. (1995). Sociocultural Transfer and its Effects on Second Language Speakers' Communication. Int. J. Intercultural Rel., 14(2), 253-265. https://doi.org/10.1016/0147-1767(94)00008-L

Miller, N. (1984). Language Problems and Bilingual Children. In N. Miller (ed.), Bilingualism and Language Disability: Assessment and Remediation (pp. 81-103). London: Chapman and Hall. https://doi.org/10.1007/978-1-4899-7238-5_4

Rafik, G. F. (2012). Some Difficulties of Teaching English Consonants for Students Whose Native Language is Arabic. Kirkuk University Journal-Humanity Studies, 7(4), 1-19.

Reiter, R. M. (1997). Sensitising Spanish Learners of English to Cultural Differences. In M. Pütz (ed.), The Cultural Context in Foreign Language Teaching (pp. 145-155). Frankfurt am Main: Peter Lang GmbH.

Ridha, N. S. (2012). The Effect of EFL Learners' Mother Tongue on their Writings in English: An Error Analysis Study. Journal of the college of Arts, 60, 22-45.

Sabbah, S. S. (2015). Negative Transfer: Arabic Language Interference to Learning English. Arab World English Journal (AWEJ), 4, 269-288. https://doi.org/10.2139/ssrn.2844015

Saville-Troike, M. (2012). Introducing Second Language Acquisition (2 ${ }^{\text {nd }}$ edn.). Cambridge: Cambridge University Press. https://doi.org/10.1017/CBO9780511888830

Searle, J. (1976). Classification of Illocutionary Acts. Language in Society, 5(1), 1-23. https://doi.org/10.1017/S0047404500006837

Searle, J. (1979). Expression and Meaning: Studies in the Theory of Speech Acts. Cambridge: Cambridge University Press. https://doi.org/10.1017/CBO9780511609213

Song, S. (2012). Politeness and Culture in Second Language Acquisition. London: Palgrave Macmillan. https://doi.org/10.1057/9781137030634

Swan, M., \& Smith, B. (2001). Learner English: A Teacher's Guide to interference and other Problems ( $2^{\text {nd }}$ edn.). Cambridge: Cambridge University Press. https://doi.org/10.1017/CBO9780511667121

Taleghani-Nikazm, C. (2006). Request Sequences: The Intersection of Grammar, Interaction and Social Context. Amsterdam: John Benjamins Publishing Company. https://doi.org/10.1075/sidag.19

Teng, M. F. (2019). Autonomy, Agency, and Identity in Teaching and Learning English as a foreign Language. Singapore: Springer Nature Singapore Pte Ltd. https://doi.org/10.1007/978-981-13-0728-7 
Trosborg, A. (1995). Interlanguage Pragmatics: Requests, Complaints and Apologies. Berlin: Mouton de Gruyter. https://doi.org/10.1515/9783110885286

Turaeva, M. (2020). The Problem of Lexical Interference of Language in Speech. Mental Enlightment Scientific Methodological Journal, 2(11), 94-100.

Uso-Juan, E., \& Martinez-Flor, A. (2008). Teaching Learners to Appropriately Mitigate Requests. ELT Journal, 62(4), 349-357. https://doi.org/10.1093/elt/ccm092

Wei, L. (2018). Pragmatic Transfer and Development: Evidence from EFL Learners in China. Amsterdam: John Benjamins B. V.

Zhu, Y. (2008). The Impact of Cultural Transfer on Cross-cultural Communication. Asian Social Science, 4(7), 142-146. https://doi.org/10.5539/ass.v4n7p142

\section{Notes}

Note 1 . The names of the Jury members, which consist of staff members specialized either in linguistics or TEFL, are listed below along with their scientific degree and place of work:

1) Asst. Prof. Haider Abdulkadum Al-Bermani, College of Education for Humanities, University of Karbala.

2) Asst. Prof. Nadia Majeed Hussein, The Technical Institute, Baghdad.

3) Asst. Prof. Dr. Mohsin Ali Shreeb, The Open Educational College, Karbala.

4) Asst. Prof Sabeeha Dehham, College of Basic Education, University of Babylon.

5) Asst. Prof. Dr. Chasib F. Abbas Al-Juouri, The Open Educational College, Diwaniyya.

6) Dr. Ahmed Muhsen Mashkour, Directorate of Education, Thi-Qar.

\section{Appendix 1: The Test}

\section{Q1/ Choose the correct choice:}

1. You and your family are eating at lunch table. The food was a little bit unsalted. You decided to ask your mother to pass you the salt:

a- Mum, can you pass me the salt, please?

b- If some salt is added, the taste would be better.

c- Mum, you might forget to add a little bit salt. Is it possible to pass me the salt?

d- Mum, may God keep you healthy, can you pass me the salt?

2. Your car has broken down and you have an emergency situation. You decided to borrow your neighbour's car:

a- Hello, Mr. (Ahmed). I see that your car is still in the garage.

b- Sorry, brother, by 'Alla, I've got a problem that needs to be solved right now. Unfortunately, my car has just broken down. Is it possible that you lend me your car?

c- I wonder if I could borrow your car. Actually, my car has just broken down and I've got an emergency.

d. Excuse me, brother, my car has broken down and I've got an emergency situation. Can I borrow your car?

3. You are a university student and this is your first lecture. You did not get in time so you missed the lecture. You decided to ask one of your classmates to get a copy of his notes. Your request would be:

a- Freshmen have always fresh brains. I've arrived late because, you know, it is the first day and I need to prepare for the lecture. Can you give me your notes to copy?

b- Can I get a copy of your notes, please? I need to prepare for the next lecture.

c- (If God wills, you got in time). Brother, would you please give me your notes to copy? If this doesn't cause you any trouble.

d- Excuse me, give me your notes to copy, please. 
4. You invite your friends to your house. Once you entered the kitchen, you found it in a mess because your little sister was making a pizza. You decided that the kitchen should be cleaned as soon as possible. Your request would be:

a- Sister, clean the kitchen, will you?

b- Clean the kitchen right now, shit!

c- Fucking clean up your shit.

d- Clean the kitchen. By 'Alla, I will hit you.

5. You ask your sister for a small favour which is to bring you a spoon with your pudding. Your request would be:

a- With God willing you are so quick. Bring me a spoon when you bring my pudding

b- Can you bring me a spoon when you bring my budding, May God keep you healthy?

c- Will you bring a spoon when you bring my budding?

d- Would you do me a favour? Bring a spoon when you bring my pudding, please.

6. You are a clerk, you got a problem in your computer. You could not get the tables to start working. You asked a workmate to help in this problem. Your request would be:

a- You know I am such an idiot about these things. Would you mind helping me please?

b- I don't know what the problem of this computer is.

c. With God willing. You are excellent in using computers. I found a problem in the tables. Come and give me a hand.

d- Brother, I can't do it myself. Can you give me a hand, please?

7. You are a university student and you forgot your pen and you needed to write some notes about the lecture. You decided to borrow a pen from your classmate. Your request would be:

a- By 'Alla, give me a pen, please.

b- Brother, can you give me a pen, if possible?

c- I wonder if I could borrow your pen, please.

d- I do not know where my pen is.

8. You are a secretary. You had an emergency situation since your kid was sick and you had to get an appointment with the doctor tomorrow. Thus, you needed an off tomorrow, but it happened that you had an off yesterday,. Your request would be:

a- I was wondering if I could have an off tomorrow. My kid is really sick.

b- Sorry, Sir. My kid is sick, you know kids are always so. Could you give me an off tomorrow, if you don't mind?

c- Peace be upon you. Sir, I know that I had an emergency yesterday, but I have an emergency situation today as well. My kid is so sick and there is no one available to take him to the doctor, except me. 'God save you', can you give an off tomorrow?

d- Hello Sir, All the documents are ready to be signed. It is too cold and thus kids are always sick.

9- You are a university student and you study hard for the next week exam. Students in a nearby room celebrate their friend's birthday and they sing songs loudly which is a thing that disturbs you. Your request would be:

a- Lessen your voices, brothers. I want to study.

b- Shut up, will you?

c- You wouldn't mind be quieter. I mean, would you?

d- No one can study here.

10. You are at your friend's apartment. While you were studying, he served you with a cup of tea. You felt that you need to drink another one because it is such a tasty cup of tea. Your request would be:

a- I've drunk a cup of tea, but I still have headache.

b- Brother, can I have another one, please?

c- God save your hands. Your tea is tasty. I want to have another one. 
d- Could I have another one, please?

11. You are a passenger and you asked the taxi driver to open the window just because you cannot stand closed atmospheres in spite of the weather's being cold outside. Your request would be:

a- Open the window, God grace your parents.

b- Excuse me, could you please open the window?

c- I cannot stand closed atmospheres.

d- Can you open the window a little bit, brother?

12. You are at a restaurant, sitting with a friend of yours. You decided to order two cups of coffee. Your request would be:

a. Bring us two cups of coffee, please.

b- Excuse me, two cups of coffee, please.

c- Can I have two cups of coffee, please?

d- May God keep you healthy, brother? Can you bring us two cups of coffee?

13. You are a university student and your doctor has a lecture with you. His voice was too low, so you and your classmates decided to request him to speak up just a little bit. Your request would be:

a- Sorry, our respectable doctor, we did not catch what you have just explained because your voice was low. God preserve you doctor, can you speak up a little bit?

b- God preserve you doctor, we could not catch your point. We were wondering if you could speak up a little bit?

c- Excuse me, doctor. Could you speak up just a little bit?

d- Doctor, is it possible that you speak up just a little bit, please?

14. You and your friend came from market. Your friend invited you to his house and it was a very hot day. Once you entered, your friend's mother served you a cold glass of juice. You still felt hot and tired and you need another glass of juice. Your request would be:

a- you opt out of the request because it is an impolite behaviour. And you wait until your friend's mother observes your need and serves you one more glass of juice.

b- I would like another one, please.

c- God saves you aunty, could I have another one?

d- Is it possible that you give me another one, please?

15. You are a customer who asks a green grocer for some strawberries. Your request would be:

a- I'd like some strawberries, please.

b- Hello, I want some strawberries, please.

c- Peace be upon you, brother. Give me some strawberries. With God willing they look ripe.

d- Some strawberries, please.

16. You have got a difficult homework. You asked your brother to help you with it. Your request would be:

a- Ahmed, help me with my homework, 'May God save you'.

b- I want to ask you something, Ahmed. Can you help me with my homework?

c- Are you doing anything at the moment? Could you help me with my homework?

d- This homework drove me crazy. I don't know how to start.

17. You are a university student and you have a problem with your term paper since it may not be handed on time. You needed to speak to your doctor who is on his way to the office. Your request would be:

a- Peace be upon you, my respectable doctor, I know that you are busy, but I have got a problem with my term paper. Can I speak to you for a minute? I was sick and I am afraid that my term paper may not be handed on time.

b- Hello, doctor. I want to speak to you for a minute, please. I have got a problem with my research.

c- Hello, doctor. I would like to speak to you for a minute, please. I got a problem with my term paper. 
d- Peace b upon you, doctor. I know that you are busy, but I've got a problem with my term paper. I was wondering if I could speak to you for a minute. I was sick and I am afraid that my term paper may not be handed on time.

18. You are a university student. It happened that the money in your pocket had been lost. You decided to borrow some money from one of your classmates. Your request would be:

a- Excuse me, can you lend me some money. I'll pay you back right away.

b- God preserve you brother, I've lost my money. Would you mind lending me some money? I will return it tomorrow in God's willing.

c- I've lost my money. Is it possible that you lend me some? I will return it tomorrow in God's willing.

d- Excuse me, I was wondering if you could lend me some money. I'll pay you back right away.

19- You work at a restaurant. It was your turn to lay the tables, but you had to leave earlier because you had to take your father to the airport. Thus, you asked one of the workers to lay them instead of you. Your request would be:

a- I want to ask you something. Can you lay the tables tonight instead of me?

b- Excuse me, is it possible to lay the tables, do you think, for me?

c- Brother, may God keep you healthy. You wouldn't mind laying the tables instead of me. I mean, would you?

d- Are you doing any thing tonight? Could you lay the tables at the moment instead of me?

20. You visit your teacher at home. You requested the teacher for a drink after a meal:

a- Sir, can you please give me a glass of water if it is not too much trouble?

b- I was wondering if it is not too much trouble if I may have a drink.

c- Sir, may God keep you healthy. Can you give me a glass of water?

d- Sir, may God keep you healthy. May I have a drink?

\section{Q2/ What would you say in each of the following situations:}

1. You are a student. You want to go back home, but there is not any bus available at the moment. You asked one of your classmates who had a car to give you a lift. It happened that he was driving to the same destination where your house is in:

2. You and your friend are in a University trip. You forgot to bring your own camera with you. You decided to ask one of your classmates to lend you his camera for a moment to take some photos:

3. You are the boss at work. You asked one of your employees to collect the documents before the banks close:

4. You are a university students and it is the first day for you in this university. You forget your phone at home and your father was too late to drive you home. All the students had left home and you decided to ask one of your lecturers whom you know to use his phone to phone your father:

5. You had just come from outside. You felt hungry and you decided to ask your little brother to get you a sandwich from a nearby sandwich shop:

6. You are a passenger on a bus. You asked someone sitting beside you to open the window:

7. You are the head manager of a particular company. You asked the junior employee of service to bring you a cup of tea:

8. You are a university student. It happened that you were carrying a large number of books with your both hands and you asked a professor whom you do not know to open the door: 
9. Your neighbour parked in an area where you cannot get your car out of the garage. You decided to ask him to move his car:

10. You are a teacher. One of your students answered in a low voice and you asked him to speak up a bit louder:

11. You are driving outside your town. Suddenly, your car did not work properly. You decided to ask for help. Thus, you stopped one young man to ask him to mend the engine for you:

12. You are an employee. You had got some work outside your town. You decided to ask your boss at work to leave early tomorrow to go home:

13. Your mother is cleaning your apartment. She needed a ladder and you decided to ask the man at a nearby store to borrow his ladder:

14. You are at the cinema. You could not see the screen because of someone sitting before your seat. You decided to ask him to move his head:

15. You are a university lecturer. You asked one of your students to explain to you and other students what subject he has chosen for his research paper:

16. You and your friend are sitting in the park. Your friend decided to walk but you preferred to sit and see the flowers. You asked him to bring you a cup of tea while he is walking:

17. You are in the street. You forgot your phone and you wanted to call your father for a very important thing. You decided to ask one of the people to use his phone to call your father:

18. You are in the market. You asked one of the sellers if he had a change for 25000 IQD:

19. You are a lecturer. You asked one of the students to go in the staff room to bring two sheets of paper:

20. Your friend will travel to another country. You went with him to the airport to say good bye. You asked him to come and see you soon.

\section{Copyrights}

Copyright for this article is retained by the author(s), with first publication rights granted to the journal.

This is an open-access article distributed under the terms and conditions of the Creative Commons Attribution license (http://creativecommons.org/licenses/by/4.0/). 